\title{
Current Understanding of Osteoimmunology in Certain Osteoimmune Diseases
}

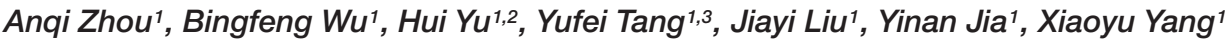 \\ and Lin Xiang ${ }^{1,2 *}$
}

1 State Key Laboratory of Oral Diseases and National Clinical Research Center for Oral Diseases, West China Hospital of Stomatology, Sichuan University, Chengdu, China, ${ }^{2}$ Department of Oral Implantology, West China Hospital of Stomatology, Sichuan University, Chengdu, China, ${ }^{3}$ Department of Orthodontics, West China Hospital of Stomatology, Sichuan University, Chengdu, China

\section{OPEN ACCESS}

Edited by: Venkaiah Betapudi,

United States Department of Homeland Security, United States

Reviewed by:

Sandro Mazzaferro,

Sapienza University of Rome, Italy

Lia Ginaldi,

University of L'Aquila, Italy

Reinhard Gruber,

Medical University of Vienna, Austria

*Correspondence:

Lin Xiang

dentistxiang@126.com

Specialty section:

This article was submitted to

Cellular Biochemistry,

a section of the journal

Frontiers in Cell and Developmental

Biology

Received: 20 April 2021

Accepted: 15 July 2021

Published: 17 August 2021

Citation:

Zhou A, Wu B, Yu H, Tang Y, Liu J, Jia Y, Yang $X$ and Xiang L (2021)

Current Understanding of Osteoimmunology in Certain

Osteoimmune Diseases.

Front. Cell Dev. Biol. 9:698068. doi: 10.3389/fcell.2021.698068
The skeletal system and immune system seem to be two independent systems. However, there in fact are extensive and multiple crosstalk between them. The concept of osteoimmunology was created to describe those interdisciplinary events, but it has been constantly updated over time. In this review, we summarize the interactions between the skeletal and immune systems in the co-development of the two systems and the progress of certain typical bone abnormalities and bone regeneration on the cellular and molecular levels according to the mainstream novel study. At the end of the review, we also highlighted the possibility of extending the research scope of osteoimmunology to other systemic diseases. In conclusion, we propose that osteoimmunology is a promising perspective to uncover the mechanism of related diseases; meanwhile, a study from the point of view of osteoimmunology may also provide innovative ideas and resolutions to achieve the balance of internal homeostasis.

Keywords: osteoimmunology, RANKL/RANK/OPG, rheumatoid arthritis, periodontitis, bone repair, dental implantation

\section{INTRODUCTION}

The skeletal system and immune system seem to be independent but are in fact inseparable and closely related. On the one hand, as the primary hemopoietic organ, bone marrow nourishes and provides a unique environment for the growth of hematopoietic stem cells (HSCs), the common origin of all types of immune cells (Walsh et al., 2018), which establishes the structural basis of regulation on the immune system by bone. On the other hand, the activity of immune cells is of great significance for the occurrence and the development of pathological bone damage diseases, such as rheumatoid arthritis (RA), periodontitis, delayed bone regeneration, and bone abnormalities in other infectious diseases. Therefore, cells from the immune and skeletal systems share the same microenvironment and interact extensively. Arron and Choi (2000) established the concept of osteoimmunology first to describe the interaction between the skeletal and immune systems, while the specific definition of osteoimmunology was not clarified. Takayanagi (2007) defined osteoimmunology and highlighted its interdisciplinarity, and the scope of osteoimmunology was extended into the interaction between a wide range of cells from the skeletal and immune systems. In recent years, with the advancements in studies on the crosstalk between the two systems and our cognition, the concept of osteoimmunology has been further 
updated. Okamoto et al. (2017) proposed that osteoimmunology emphasized the interaction between the two systems from the macro level to the micro level as well as the inner mechanism in both physiologic and pathologic conditions, and it involved the research progress on therapeutic strategies for relevant diseases, which is a relatively comprehensive summary of osteoimmunology so far. Since osteoimmunology builds the bridge between the skeletal and immune systems, it is of great value to discuss the regulatory role that osteoimmunology plays in a series of essential biological processes, suggesting promising perspectives for studies and potential therapies related to skeletal and immune system diseases.

The skeletal system and immune system share various cytokines and signaling pathways. Scientists have uncovered the significant role of the receptor activator of nuclear factor kappa $B$ ligand (RANK ligand or RANKL)/RANK/osteoprotegerin (OPG) axis in osteoimmunomodulation in the past few years (Okamoto et al., 2017; Tsukasaki and Takayanagi, 2019). Besides, there are an increasing number of novel studies aiming to reveal more promising key cytokines and signaling pathways that connect the skeletal and immune systems and are involved in the research scope of osteoimmunology, such as tumor necrosis factor- $\alpha$ (TNF- $\alpha)$ (Bertolini et al., 1986), interferon- $\gamma$ (IFN- $\gamma)$ (Smith et al., 1987), interleukin-1 (IL-1) (Gowen et al., 1983), IL-4 (Shioi et al., 1991), IL-6 (Löwik et al., 1989), IL-17 (Kotake et al., 1999), IL-20 (Hsu et al., 2011), bone morphogenetic protein (BMP) (Lories et al., 2003), sphingosine-1-phosphate (S1P)-S1P receptor-1 (S1PR1) signaling (Xiao et al., 2019), Notch signaling (Liotta et al., 2008), mitogen-activated protein kinase (MAPK) pathway (Chae et al., 2001), dependent or independent on RANKL/RANK/OPG signaling pathway, which further enriches our understanding of osteoimmunology.

In this review, we will summarize the many interactions between cells of the skeletal and immune systems during the development of certain typical osteoimmune diseases as well as the molecular mechanism behind them according to the mainstream advancing studies. We would like to stress the importance of discussing these biological processes from the perspective of osteoimmunology in future research, so as to achieve the balance of internal homeostasis in the skeletal and immune systems.

\section{CO-DEVELOPMENT OF THE SKELETAL AND IMMUNE SYSTEMS}

\section{Shared Molecular Mechanism Between Osteoimmune Cells in Osteoclastogenesis}

Osteoclasts are the dominant bone resorptive cells in bone metabolism (Figure 1). The dynamic balance of bone formation and resorption driven respectively by the activity of osteogenic cells and osteoclasts is the key to physiologic bone remodeling and bone homeostasis. Under the physiological conditions, osteoclasts are multinucleated giant cells formed by the fusion of monocyte/macrophage precursor cells derived from myeloid progenitor cells in bone marrow with the indispensable involvement of macrophage colony-stimulating factor (M-CSF) and RANKL (Kong et al., 1999; Suda et al., 1999). Immature dendritic cells (DCs) are also recognized as the precursor of osteoclasts besides monocyte/macrophage precursor cells (Rivollier et al., 2004; Gallois et al., 2010), while researchers have revealed that the hypotheses of monocyte-origin and DCorigin are probably not mutually exclusive. Tsukasaki et al. (2020) discovered the transient expression of CD11c (the marker of DCs) during the process of osteoclastogenesis by the scRNAseq analysis, and the specific deletion of RANK in CD11c cells led to inhibition of osteoclastogenesis, which strongly suggested that DC-like precursors were the indispensable transitional state between monocytic precursors and the mature osteoclasts. Furthermore, in the past few years, accumulating evidence showed that certain mesenchymal cells also serve as RANKLproducer cells that are required for bone metabolism and the progress of osteoimmune diseases. At the beginning, osteoblast is recognized as the cellular source of RANKL that plays an essential role in osteoclastogenesis (Yasuda et al., 1998). The dynamic tracking of RANKL in vitro has revealed that RANKL mRNA and protein are localized in osteoblasts and immature osteocytes, and the expression of RANKL decreases with the maturation of osteoblasts (Kartsogiannis et al., 1999), while some studies have indicated the opposite results that the main producers of RANKL in bone remodeling are hypertrophic chondrocytes and osteocytes rather than osteoblasts or their progenitors, which do not contribute to osteoclastogenesis (Xiong et al., 2011). A more specific description on the localization of cellular source of RANKL during the development of osteoclasts may need further clarification. Besides, the latest evidence demonstrated another committed cell population from adipogenic lineage that regulates bone resorption via RANKL. Yu et al. identified novel marrow adipogenic lineage precursors (MALPs), making up a ubiquitously distributed 3D network in bone marrow to maintain bone marrow capillary structure and suppress osteogenesis. The recent published paper further revealed that MALPs expressed RANKL and showed spatial specificity in controlling the osteoclastogenesis during bone remodeling, confirming the role of MALPs in bone resorption in physiologic and pathologic states (Yu et al., 2021). Additionally, a unique subset of macrophages named as arthritis-associated osteoclastogenic macrophages (AtoMs) was identified, which functioned as the precursor of osteoclasts in arthritis (Hasegawa et al., 2019). What is more, it is worth noticing that monocyte/macrophage precursor cells from different origins are tissue-specific. Recently, scientists have revealed that yolk-sac macrophages of erythromyeloid progenitor (EPM) origin produced neonatal osteoclasts that are independent of HSC lineage (Gomez Perdiguero et al., 2015; Yahara et al., 2020), providing a further and more precise explanation of the developmental mechanism of osteoclasts.

Moreover, over the last few years, researchers have been paying more attention to the function of cells involved in osteoimmunology as well as the underlying molecular mechanism and associating it with dysregulated bone homeostasis and bone diseases (Yang and Wan, 2019). M1/M2 dichotomy is well known as the classic classification pattern 


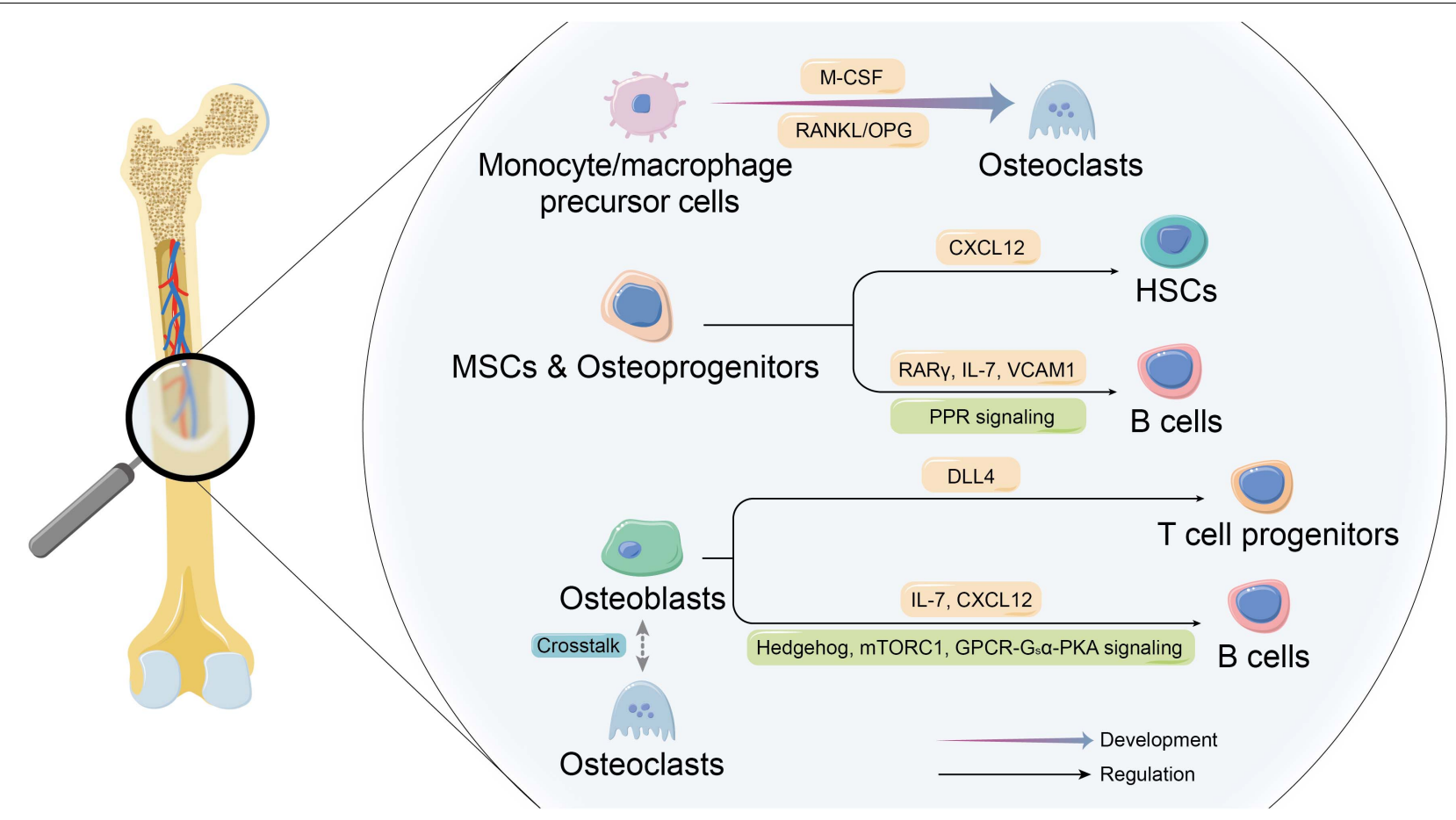

FIGURE 1 | Co-development of skeletal and immune systems. The co-development of the skeletal system cells and immune system cells constitutes the basis of theory of osteoimmunology. On the one hand, certain immune cells are the essential origin of osteoclasts. On the other hand, skeletal system cells make up the unique niches in bone marrow to participate in forming the indispensable microenvironment for immune cells and affect the their development and biological behaviors.

of macrophage that immature macrophages are subdivided into pro-inflammatory $\mathrm{M} 1$ and anti-inflammatory/regulatory M2 according to the activator, surface maker, secretion, and function, playing their distinct roles in regulating osteoimmune microenvironment (Yamaguchi et al., 2016; Brown et al., 2017). Besides, the diversity between the two subtypes also includes the osteoclastogenic property. Yang et al. (2019) observed the osteoclastogenic potential of the two subtypes, and the results suggested that M2 macrophages were more efficient osteoclast precursors than M1 macrophages, which was attributed to a higher level of interferon regulatory factor 5 (IRF5) expression. Similarly, in the pathological condition, with the decreased level of estrogen and elevated level of RANKL, M2 macrophages are stimulated to differentiate to osteoclasts in ovariectomized (OVX) mice, while M1 macrophages are not influenced, hence the improved M1/M2 ratio, which can be rescued by estrogen or estrogen receptor $\alpha(\mathrm{Er} \alpha)$-selective agonist (Dou et al., 2018). In addition to the discrepancy of osteoclastogenic potential, the direct regulatory role of the two subtypes on osteoclast precursors cannot be ignored. M1 macrophages were discovered to inhibit osteoclastogenesis of RAW264.7 cells and bone marrow cells via secreting IFN- $\gamma$ and IL-12, while M0 and M2 were not, contributing to the complexity of osteoclastogenesis mechanism in settings of osteoimmune diseases in which infiltration of macrophages is involved (Yamaguchi et al., 2016).

\section{Osteoblast Lineage Provides Indispensable Unique Niches for Immune Cells}

Bone marrow offers the specific microenvironment where immune cells differentiate, which is known as "niches." These niches mainly consist of heterogeneous stromal cells, many of which are of mesenchymal origin, including various subsets of osteoblast lineage (Panaroni and $\mathrm{Wu}, 2013$ ), establishing the histological basis of osteoblast lineage playing a supportive and collaborative role in the development, maintenance, and mobilization of immune cells and their precursors. For a long time, scientists have been committed to the study on the characteristics of immune cells in the special bone marrow niches, while the growth mechanism of immune cells and the specific regulatory function of niches are still not fully clarified.

Osteoblast lineage cells of different maturity stages play different roles, and the precise regulation at different stages of osteoblastogenesis is required for optimal development procedure of immune cells (Wu et al., 2008). According to an article published on Nature, after selectively depleting $\mathrm{Nestin}^{+}$mesenchymal stem cells (MSCs) in mice, MéndezFerrer et al. (2010) observed a $\sim 4$-fold reduction in the activity of bone marrow HSCs. In the absence of Nestin ${ }^{+}$MSCs, the homing of HSCs to bone marrow was markedly reduced, which might be related to the considerably high level of key gene 
expression that regulates HSC behaviors in MSCs. It is further demonstrated that CXC-motif chemokine ligand 12 (CXCL12) in early mesenchymal progenitors is essential for the maintenance of HSCs (Sugiyama et al., 2006), and B lymphopoiesis is regulated by MSCs retinoic acid receptor $\gamma(\mathrm{RAR} \gamma$ ) activity (Green et al., 2018). Moreover, parathyroid hormone (PTH)/PTHrelated peptide receptor (PPR) signaling in osteoprogenitors plays an essential role for B lymphopoiesis by expressing IL-7 and the mobilization of $\mathrm{B}$ cells by expressing vascular cell adhesion molecule 1 (VCAM1) (Panaroni et al., 2015).

The effects of osteoblasts on making up the unique microenvironment for immune cells seem to be understood more thoroughly. Scientists have proved that regulation of B lymphopoiesis is mediated by Hedgehog ( $\mathrm{Hh}$ ) signaling, mechanistic target of rapamycin complex 1 (mTORC1) signaling, and $G$ protein-coupled receptors (GPCR)- $\mathrm{G}_{s} \alpha$-protein kinase $A$ (PKA) pathway in osteoblasts, thus influencing the expression of key cytokines that support the development of B cells, such as IL7 or CXCL12 (Wu et al., 2008; Lu et al., 2018; Martin et al., 2018; Wang et al., 2018). Moreover, the generation of T-cell progenitors has been demonstrated to be promoted by osteoblasts-derived Notch ligand delta-like 4 (DLL4).

It is also worth noticing that osteoclast is an important component of the niche for immune cells. It has been shown that osteoclasts contribute to mobilization of HSCs by influencing endosteal niche components (Kollet et al., 2006), and the role of osteoclasts as niches for immune cells can also be suggested indirectly by $\mathrm{B}$ lymphocytopenia in osteopetrosis (Mansour et al., 2011). However, there are some other studies that show opposite conclusion. For example, osteopetrotic mice present normal mobilization of HSCs in response to the stimulation of granulocyte CSF (G-CSF) (Miyamoto et al., 2011), suggesting the regulatory effects of osteoclasts on immune cells in bone marrow may be applicable in certain conditions. Furthermore, rather than regulating the fate of immune cells directly, osteoclasts contribute to supporting the development of immune cells by influencing biologic behaviors of osteoblasts, thus changing the bone marrow microenvironment (Mansour et al., 2011, 2012). In a word, the skeletal system provides indispensable unique niches in bone marrow for growth of immune cells through a variety of direct and indirect ways, and the study on osteoimmune niche cells interaction is promising to reveal the inner mechanism of immune cells development, so as to achieve the balance of bone marrow internal homeostasis and provide innovative ideas and resolutions for correlated diseases.

\section{OSTEOIMMUNOLOGY IN TYPICAL BONE ABNORMALITIES AND BONE REGENERATION}

\section{Rheumatoid Arthritis}

The interdisciplinary study on RA seems to be the most advanced among osteoimmune diseases (Figure 2). The main pathological features of RA include proliferation of synovial lining cells, infiltration of an abnormally large number of inflammatory cells, advanced angiogenesis, pannus formation, and destruction of cartilage and bone tissue.

As for the cellular and molecular mechanisms, the activation of $\mathrm{T}$ lymphocytes induced by antigen-presenting cells (APCs) is the initial and key step to stimulating bone resorption in the inflamed synovium. $\mathrm{T}$ helper $17\left(\mathrm{~T}_{\mathrm{H}} 17\right)$ cell that is defined by characteristic expression of $\mathrm{IL}-17$ is recognized as a specialized subset that induces osteoclastogenesis at the interface of bone and activated immune system after examining a variety of $\mathrm{T}_{\mathrm{H}}$ cells (Sato et al., 2006). Induced by elevated IL-17, various innate immune cells like macrophages, mast cells, and neutrophils further impact on RANKL/OPG ratio and then the development of osteoclasts by secreting effective osteoclastic cytokines such as TNF- $\alpha$, IL-1, and IL-6 (RoserPage et al., 2018; Tsukasaki and Takayanagi, 2019). Moreover, as a group of lymphocytes that negatively regulates immune response, regulatory $\mathrm{T}$ (Treg) cells usually play an important role in restraining excessive immune response and maintaining microenvironment homeostasis, which has been verified in Treg cells from human tissue (Delacher et al., 2021). Treg cells are the crucial component in $\mathrm{T}$ cells that mediated antiosteoclastogenesis in RA, and ameliorating the imbalance of Treg/ $\mathrm{T}_{\mathrm{H}} 17$ has become a popular therapeutic target in forefront studies (Geng et al., 2017; Jin et al., 2018; Shi et al., 2020; Shang et al., 2021). Moreover, Forkhead box protein P3 (FOXP3) is considered as a specific transcription factor that plays a crucial role in the development and the function of Treg cells by regulating different genes directly, and researchers have proposed its relations to the pathogenesis of RA. Nie et al. (2013) discovered that TNF- $\alpha$ stimulated the transcriptional and enzymatic activity of protein phosphatase 1 (PP1) in the inflamed synovium, leading to dephosphorylation at the specific site in FOXP3, resulting in the impaired protective function of Treg cells and the imbalance between $\mathrm{T}_{\mathrm{H}} 17$ and Treg cells. Meanwhile, Komatsu et al. (2014) revealed that the instability of FOXP3 expression was also attributed to excessive IL-6 produced by synovial fibroblasts, another essential cell population involved in the basic osteoimmunological progress of RA. The mechanism of synovial fibroblasts contributing to immune cells-mediated osteoclastogenesis in RA includes not only their weakened capacity to inhibit the activity of $\mathrm{T}_{\mathrm{H}}$ cells but also the stimulated expression of inflammatory factors by IL-17 (Hirota et al., 2018; Kaul et al., 2020), which form a vicious circle in the osteoclastogenesis and aggravate bone damage of individuals with RA. In particular, it has been demonstrated that synovial fibroblasts serve as the main source of RANKL for bone destruction in RA instead of T cells (Danks et al., 2016). Additionally, with the development of genomic medicine, scRNA-seq has become a popular method to identify the characteristics and biomarkers of complex disease such as RA. Based on the recent scRNA-seq analyses of inflamed synovium samples of RA mouse models and patients, sublining fibroblasts are considered as a major source of pro-inflammatory factors like IL-6, and the expansion of a distinct subset of $\mathrm{PDPN}^{+} \mathrm{CD}^{-} 4^{-} \mathrm{THY}^{+}$sublining fibroblasts may be pathogenic in RA tissues, suggesting the potential therapeutic target of RA (Mizoguchi et al., 2018; Gawel et al., 2019; Zhang et al., 2019). 


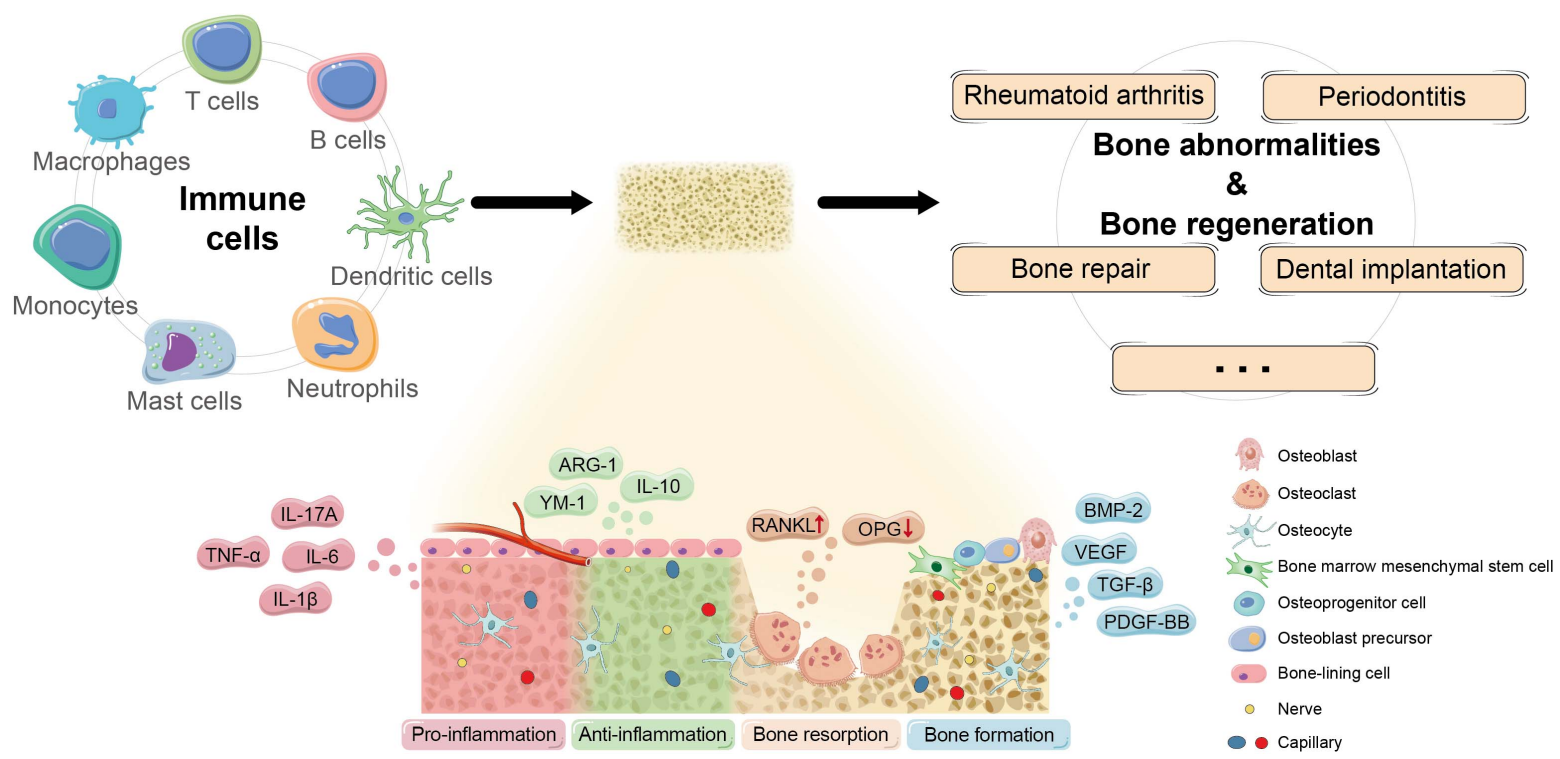

FIGURE 2 | Potential mechanism of osteoimmunomodulation in bone abnormalities and bone regeneration. Immune cells regulate the occurrence and development of bone abnormalities and bone regeneration by impacting the osteoimmune microenvironment through a series of key molecules and pathways to influence the biological behaviors of skeletal system cells. Currently, more and more promising cytokines and signaling that participate in osteoimmunomodulation have been discovered, such as pro-inflammatory TNF- $\alpha$, IL-1 $\beta$, IL-6, and IL-17A; anti-inflammatory IL-10, ARG-1, and YM-1; osteoclastogenic RANKL/OPG; and bone repair signals like TGF- $\beta$, BMP-2, PDGF-BB, and VEGF.

The latest evidence also indicates that the position identity of synovial fibroblasts is regulated by Notch signal from endothelial cells (Wei et al., 2020).

Scientists have uncovered the molecular mechanisms of autoimmune response in RA relatively clearly, while the potential therapeutic approach of damaged bone needs further discovery. Culemann et al. (2019) identified a group of $\mathrm{CX}_{3} \mathrm{C}$ motif chemokine receptor 1-positive $\left(\mathrm{CX}_{3} \mathrm{CR}^{+}\right)$tissue-resident macrophages in synovial lining and proposed that they could form a dynamic membrane-like structure by tightly connecting with each other, establishing a protective barrier to inhibit the inflammatory reaction. Such results uncovered the multiple functions of macrophage in addition to its pro-inflammatory effect in RA, as well as suggested the promising therapeutic value of macrophage. As mentioned before, TNF- $\alpha$ induces impaired function of Treg cells via FOXP3 and inhibits their protective role in the synovium, while TNF receptor type II (TNFRII), the receptor type that mediated the anti-inflammatory effects of TNF, has been demonstrated to participate in maintaining the stable expression of FOXP3, suggesting that the potential mechanism of anti-TNF agent in RA treatment may be attributed to the expansion of TNFRII ${ }^{+}$Treg cells (Santinon et al., 2020). Moreover, because oxidative stress and RA are closely related pathologically, antioxidant therapy has also been considered as a prospective strategy of RA (Khojah et al., 2016; Jabbari et al., 2020). In addition, the Hippo-Yes-associated protein (YAP) signaling pathway regulates the expression of target genes to affect a series of physiological activities through responding to other intracellular and extracellular signals, consequently playing important roles in cell proliferation, differentiation, and apoptosis, which suggests its indispensable impacts on osteogenesis and immune regulation (Liu et al., 2016; Xiang et al.,
2018; Wang et al., 2019). Therefore, it is remarkable that there is extensive crosstalk between Hippo signaling and oxidative stress signaling, and a positive feedback mechanism between YAP and reactive oxygen species (ROS) in oxidative stress disease has been proven (Li et al., 2019; Zheng et al., 2020). Recent researches have shown that the suppression of YAP, the main effector of Hippo pathway, leads to inhibiting the pathogenic behavior of fibroblast synovial cells via reducing their migration and invasion, which suggests Hippo-YAP signaling as a prospective therapeutic target of RA (Bottini et al., 2019; Zhou W. et al., 2020). Further study is encouraged to concentrate on the crosstalk between Hippo-YAP and oxidative stress in osteoimmune regulation to RA, as well as the prospective value of antioxidant therapy it mediates.

\section{Periodontitis}

Apart from periodontitis, there are few conditions when infection takes place around the bone, which makes periodontitis a unique disease in osteoimmunology (Tsukasaki, 2020). Unlike autoantigen-induced RA, periodontitis starts with polymicrobial synergy and dysbiosis (Kuboniwa et al., 2017), which trigger innate immune response via bacteria and their components like lipopolysaccharide (LPS). LPS is the activator of M1 macrophage, which, as mentioned before, is the pro-inflammatory subtype, secreting pro-inflammatory cytokines like TNF- $\alpha$ and IL-1 $\beta$, thus stimulating inflammation chronic protraction. More than macrophages, DCs and T lymphocytes are also involved in the development of periodontitis. A cross-sectional study suggests that enhanced expression of IL-6 contributed to promoted number of immature DCs infiltrating in patients' periodontal tissue and in turn act on inflammatory response, though with the development of the disease, the number of these cells 
would gradually decrease (Souto et al., 2014). Moreover, clinical trials also show the increased number of peripheral and local $\mathrm{T}_{\mathrm{H}} 1$ and $\mathrm{T}_{\mathrm{H}} 17$ lymphocytes, the essential $\mathrm{T}_{\mathrm{H}}$ cell populations in nuclear factor kappa B (NF- $\mathrm{B})$-dependent pathogenesis of periodontitis, as well as promoted the expression level of T-bet, IFN- $\gamma$, and IL-17A in chronic periodontitis (Chen et al., 2016; Monasterio et al., 2019). Specifically, like macrophages, under the stimulation from bacteria and its proteins, DCs also induce $\mathrm{T}_{\mathrm{H}} 1$ or $\mathrm{T}_{\mathrm{H}} 17$ lymphocytes to upregulate the level of TNF$\alpha$ and IL- $1 \beta$, while they activate Th2 and Treg cells to play a protective role against inflammation and bone destruction simultaneously in periodontal microenvironment (Song et al., 2018). Activated by IL-1 $\beta$, IL-6, and IL-23, $\mathrm{T}_{\mathrm{H}} 17$ cells produce IL-17 family cytokines including IL-17A, which is demonstrated to be the primary mediator of immunopathology in the context of periodontitis and periodontitis-related systemic diseases (Moutsopoulos et al., 2012; Dutzan et al., 2018; Samuel et al., 2019), while IL-17E, another subtype of IL-17, may play an opposite role in the occurrence and development of periodontitis (Awang et al., 2014). In addition, a Tregs- $\mathrm{T}_{\mathrm{H}} 17$ conversion occurs during inflammation of periodontitis, and the reduction of the conversion has been considered as an effective target for periodontitis therapy (Rajendran et al., 2019). Stimulated macrophages, DCs, and T cells promote the expression level of RANKL in periodontal ligament cells and osteoblasts through their corresponding pro-inflammatory cytokines so as to initiate bone resorption performed by osteoclasts, with OPG being degraded as well (Tsukasaki, 2020), resulting in reduced RANKL/OPG ratio, which leads to alveolar bone lesion even tooth loss. Nowadays, there are more and more advanced researches focusing on the potential key molecule or signaling pathway targeted at regulating osteoimmune microenvironment in periodontitis (Goes et al., 2019; Li et al., 2020; Wang L. et al., 2020), which may provide novel perspectives and contribute to the therapeutic approaches for periodontitis based on osteoimmunomodulation. For instance, in a recent study, $\mathrm{Wu}$ et al. (2020) revealed the new AKT2/c-Jun N-terminal kinase (JNK)1/2/c-jun and AKT2/miR-155-5p/DET1/c-Jun signaling pathways that played a role in altering macrophage polarization and regulating periodontitis inflammation and AKT2 promoted M2 polarization of macrophages, suggesting a novel strategy for periodontitis treatment. As mentioned before, $\mathrm{T}_{\mathrm{H}} 1$ and $\mathrm{T}_{\mathrm{H}} 17$ are both vital in aggravating periodontitis, while the $\mathrm{T}_{\mathrm{H}} 17$ pathway has been found to be more predominant in apical periodontitis in diabetic rats than $\mathrm{T}_{\mathrm{H}} 1$ pathway, suggesting a more precise target in pathological mechanism of individuals with both apical periodontitis and diabetes (Samuel et al., 2019).

\section{Bone Repair}

Immune modulation has been considered as a therapeutic strategy in bone regeneration for a long time. The process of bone repair follows a certain procedure that reduces to activation, resorption, and formation with the involvement of a variety of bone and immune cells in coordination.

In recent years, more and more attention has been paid to the role of macrophages in bone remodeling and targeting osteogenic cell-macrophage interaction, which have been proved as effective strategies to regulate the fate of stem and progenitor cells so as to facilitate bone repair. Besides, the cellular interaction and signal crosstalk are reflected not only between macrophages and osteogenic cells but also between macrophages and angiogenic cells, with the latter playing a regulatory role in bone metabolism in an indirect manner (Dohle et al., 2014). Macrophages recruit tissue repair cells such as MSCs and fibroblasts by secreting key cytokines and chemokines and ultimately accelerating the procedure of bone regeneration surrounding the bone defect. It has been found that macrophages polarize along a transient polarization spectrum to adapt and react to distinct microenvironment (Brown et al., 2017). As mentioned before, classically activated macrophages and alternatively activated macrophages are the two mainstream subtypes of macrophages commonly known as M1 and M2, which are marked by CD86 and CD206/CD163, respectively (Goerdt and Orfanos, 1999; Mantovani et al., 2002; Mosser and Edwards, 2008). Stimulated by LPS and IFN- $\gamma$, M1 macrophages secrete pro-inflammatory factors like TNF- $\alpha$, IL-1 $\beta$, IL-6, IL- 8 , and inducible nitric oxide synthase (iNOS) to aggravate the process of inflammation and lead to tissue destruction. On the contrary, M2 is induced by IL-4 and IL-13, participating in inhibiting inflammation progress and promoting angiogenesis and tissue remodeling via secreting antiinflammatory factors such as IL-10, ARG-1, and YM-1 as well as tissue repair signals like transforming growth factor- $\beta$ (TGF$\beta$ ), BMP-2, platelet-derived growth factor-BB (PDGF-BB), and vascular endothelial growth factor (VEGF) (Zhou A. et al., 2020). Although there are more and more subtypes of macrophages and other categories that have been proposed (Mantovani et al., 2004; Murray et al., 2014; Chávez-Galán et al., 2015), the classic M1/M2 dichotomy is still popular and practical in recent work (Wang C. W. et al., 2020; Wu et al., 2020), which is likely attributed to the certain hallmarks of M1 and M2 phenotype that can be observed. Moreover, there is some evidence showing that M1/M2-related genes participate in the dynamic procedure of bone regeneration on bone-implant interface (Yuan et al., 2020). Therefore, it is of great value to further clarify the mechanism of macrophagemediated bone metabolism and conceptualize the promotion of M1 to M2 transformation as a potential method of bone repair.

Another strategy of studying monocyte/macrophagelineage cells mediated bone repair nowadays is focusing on a specific subpopulation. Tartrate-resistant acid phosphatasepositive $\left(\mathrm{TRAP}^{+}\right)$cells represent bone resorbing cells in bone metabolism and are of particular interest to scientists for a long time. Several recent studies have revealed the multiple functions of these cells. Gao et al. (2019) proved that macrophage-lineage $\mathrm{TRAP}^{+}$cells secrete PDGF-BB to recruit periosteum-derived cells (PDCs) and upregulate the expression of periostin, promoting periosteal osteogenesis and maintaining periosteum homeostasis. Moreover, Vi et al. (2018) identified differential proteins secreted by young and aged macrophages, among which low-density lipoprotein receptor-related protein 1 (Lrp1) was produced by young macrophages and played a positive role in coordinating bone fracture healing, suggesting a novel strategy for rejuvenation of bone repair.

More than macrophages, $\mathrm{T}$ cells of adaptive immune response also actively participate in the process of bone repair. In 
the early stage of inflammation, $\mathrm{T}$ lymphocytes are rapidly recruited to the injured site, among which the cytotoxic $\mathrm{T}$ lymphocytes are relatively abundant (Könnecke et al., 2014; Tätting et al., 2017). The coordinated inflammatory reaction is an inevitable procedure in regular process of bone repair. The initial infiltration of $\mathrm{T}$ cells will gradually disappear, and the second wave gathers in the callus about 2 weeks after bone fracture to play a repairing role and support bone regeneration (Könnecke et al., 2014). Different populations of T cells have different impact, and $\mathrm{T}_{\mathrm{H}} 1$ and $\mathrm{T}_{\mathrm{H}} 17$ are usually regarded as pro-inflammatory subtypes and $\mathrm{T}_{\mathrm{H}} 2$ and Treg cells are anti-inflammatory ones (Tian et al., 2021). Although the understanding of the paradigm has been updated and enriched now, it is well acknowledged that the abnormal transformation of T-cell subsets leads to prolonged inflammatory reaction and unsatisfactory repairing outcome, and their balance is particularly important for favorable bone regeneration (Schlundt et al., 2019). Additionally, $\gamma \delta \mathrm{T}$ cells were discovered to contribute to bone healing in recent years. After bone injury, the number of $\gamma \delta \mathrm{T}$ cells grows rapidly, and they secrete IL-17A to promote osteogenic differentiation (Ono et al., 2016), which may be stimulated by IL-1 $\beta$, IL-23, complement C5a, etc. (Sutton et al., 2009; Han et al., 2011), while there are still many mysteries of the molecular mechanism that needs further exploration.

On the one hand, the findings above suggest that the mechanism of monocyte/macrophage lineage cells and $\mathrm{T}$ cells in regulating bone regeneration deserves further clarification. On the other hand, more attention could be paid to the interaction between innate and adaptive immune systems that are involved in the procedure of bone repair as well.

\section{Dental Implantation}

In fact, the osseointegration of dental implants is essentially the process of bone repair that occurs on bone-implant interface and follows similar biological procedures, which osteogenesis, angiogenesis, and immune response-related cells and bioactive factors are involved in, synergizing the procedure of periimplant bone repair. The immune response driven by infiltrated cells surrounding the implants is critical for early and longterm stabilization of osseointegration. Dynamic tracking of periimplant region has revealed that as soon as the implantation occurs, coagulation response is induced and innate immune response follows during the first 4 weeks, and then bone remodeling is initiated (Vanegas-Acosta et al., 2010; Trindade et al., 2018). In peri-implant microenvironment, lack of immune response leads to residual cellular debris after implantation, which impairs osseointegration; on the contrary, the continuous activation of the immune system results in delayed bone regeneration and even osseointegration failure (Williams, 2008; Klopfleisch, 2016). Therefore, regulating the microenvironment is the crucial point, and it is necessary to closely follow the immune response of peri-implant immune cells to the changes in the local microenvironment.

However, what is special about the study on osteoimmunology-mediated implant osseointegration compared with regular bone repair is that osseointegration includes foreign-body reaction (FBR) to titanium implants, so we cannot ignore the inevitable impact of artificial biomaterial to mineral homeostasis of the jaw. Trindade et al. (2018) observed from the histologic and molecular levels and discovered that M2 macrophages were induced with initial osteogenesis at 10 days after the implantation occurred; and the innate immune system including the complement system, neutrophils, M1 and M2 macrophages, and group 2 innate lymphoid cells were triggered at 4 weeks with more mature and organized cortical bone formation. Until now, dentists still face the dilemma of undesirable biocompatibility and commit to designing a clinical-friendly implant surface and exploring effective methods to blend bioactive factors in dental implants. In recent years, the osteoimmunomodulation has been viewed as an available strategy in the implant modification instead of enhancing osteogenesis directly (Gao et al., 2020; Zhao et al., 2021; Zhu et al., 2021), and we propose that in future study, researchers can further explore the synergistic effect of osteogenesis, angiogenesis, immune response, and even neurogenesis to accelerate the osseointegration and promote the stability of dental implants. Besides FBR, peri-implant mucositis and peri-implantitis caused by bacteria invasion also draw clinicians' attention for their potential impacts on stable osseointegration, while recent studies questioned if the cause-effect relationship really existed between plaque accumulation and the occurrence of peri-implant inflammation and between peri-implant inflammation and marginal bone loss (Albrektsson et al., 2019; Coli and Jemt, 2021). These ambiguous issues need further clarification by clinical trials and long-term follow-up.

Moreover, researchers should consider the physiological particularity of the jaw. First of all, the maxilla develops through intramembranous ossification, and the mandible grows through intramembranous and endochondral ossification (Jiang et al., 2014), whereas the growth of long bone such as the femur, another commonly used model in the study on implant osseointegration besides the jaw, accords with endochondral ossification. On the other hand, the osteogenic property of intramembranous ossification may be influenced by developmental origins. Ichikawa et al. (2015) found the superior bone regenerative capacity of the periosteum of the jaw compared with periosteum derived from other sites, presumably since the jaw maintains some properties of neural crest that contribute to better bone repair outcomes. In a word, the discrepancy in the osteogenic properties may be attributed to the "site diversity" of bone tissue, but the underlying mechanisms still need further clarification. Therefore, we suggest that careful consideration should be given to the choice of animal models and cell sources in studies on osteoimmunology-mediated osseointegration in vivo and in vitro.

\section{OSTEOIMMUNOLOGY IN OTHER SYSTEMIC DISORDERS}

Based on the clarified pathological mechanism of typical osteoimmune abnormalities, we should be aware that the codependent relationship of the skeletal and immune systems is also reflected in other systemic diseases, which are not 
fully understood. More importantly, osteoimmunology may provide a novel perspective to investigate inner mechanisms as well as to develop potential therapeutic targets for these diseases. Therefore, osteoimmunology is a theory that will not answer the whole question but will put it into a broader and multidimensional context (Figure 3).

\section{Mobilopathy in Diabetes}

Among the systemic diseases with possible relations with osteoimmunology, "mobilopathy" described in diabetes is also reported as an underlying pathologic condition of bone niche dysfunction. The term of "mobilopathy" was first promoted by DiPersio (2011) in order to describe the failed mobilization of hematopoietic stem/progenitor cells (HSPCs) after cytokine treatment or chemotherapy, which may be associated with the female sex, agedness, etc. Besides, mobilopathy also leads to damaged endothelialization and vascular repair, and nowadays increased mortality of patients with diabetes is mainly attributed to ischemic vascular diseases (Vasam et al., 2017). Researchers have found that due to the perturbed microenvironment of bone marrow niche and interrupted dynamic regulation of CXCL12 expression, impaired mobilization of HSPCs from bone marrow to peripheral circulation is more likely to occur in individuals who are diagnosed with diabetes (Ferraro et al., 2011; Albiero et al., 2019). In the last decade, some researchers are committed to clarifying the molecular mechanism and developing novel therapeutic approach for diabetic cell mobilopathy. Fadini et al. (2013) discovered that the impaired HSPCs mobilization in diabetes was influenced by the dysregulation of DPP-4, a regulator of stromal cell-derived factor- $1 \alpha(\mathrm{SDF}-1 \alpha)$, in a tissue-specific manner. Additionally, the excessive expression of oncostatin M (OSM) by M1 bone marrow-derived macrophages induces CXCL12 expression, which contributes to mobilopathy in diabetes (Albiero et al., 2015). Further study indicates that role of OSM is played though OSM-p66Shc signaling, and targeting OSM-p66Shc axis may be a prospective strategy to ameliorate the mobilization of HSPCs (Albiero et al., 2019). What is more, mobilopathy can also be reflected in the impaired mobilization property of bone marrow-derived MSCs (BMSCs) in patients with type 2 diabetes, leading to inhibited bone repair and regeneration. Since it has been found that adiponectin (APN) can promote mobilization of BMSCs via the key mobilizing chemokine SDF-1, systemic infusion of APN has been demonstrated as a promising method to rescue diabetic mobilopathy and restore normal bone healing ability (Yu et al., 2015).

\section{Inflammatory Bowel Disease}

Destruction of bone tissue is regarded as a common comorbidity of inflammatory bowel disease (IBD), which has been found to be affected by the abnormal osteoimmune microenvironment in recent years. Elevated concentrations of inflammatory factors are transported via the circulatory system and play a destructive role in regular bone metabolism, changing the protein profile in charge of bone formation and resorption and leading to osteoporosis in IBD patients (Metzger et al., 2017; van Bodegraven and Bravenboer, 2020). What is more, Ciucci et al.
(2015) found that $\mathrm{T}_{\mathrm{H}} 17$ TNF- $\alpha^{+}$cells migrated to bone marrow and promoted the recruitment of osteoclast progenitors during the process of IBD, and T cells probably mediated the crosstalk between inflamed intestine and destructed bone (Sylvester, 2017). Narayanan et al. (2018) found paralleled upregulated level of TNF- $\alpha$ and RANKL in gut and bone and thereby developed a novel holistic therapeutic approach dependent on the decrease of TNF- $\alpha$ and RANKL, suggesting the importance of paying attention to the change of immune microenvironment in bone in IBD treatment.

\section{Cancer}

Cancer can be viewed as an important component of osteoimmunology field too. Classic osteoimmune signaling such as RANK/RANKL/OPG axis has shown its potential as the target of treatment and drug development for cancer (Croucher, 2001; Miller et al., 2014; Takayama et al., 2017). In recent years, there are researches that link osteoimmunology and cancer with other promising signaling molecules such as mTOR, estrogenrelated receptor $\alpha(\mathrm{ERR} \alpha)$, and IFN signals (Irelli et al., 2019; Bouchet et al., 2020; Owen et al., 2020). Besides primary bone tumor, bone is also one of the most common metastasis sites, and the osteoimmune microenvironment of bone tissue can play a supportive role in promoting the progression of tumor in various cases. The pharmacological effects of several antitumor drugs are produced by changing the bone marrow microenvironment since cancer needs a unique metastatic niche in bone marrow to survive (Owen and Parker, 2019). For example, E-selectin is considered as an effective adjuvant therapeutic drug to disrupt the interaction between cancer cells and bone marrow, especially in the cancers metastasizing to the bone, stressing the importance of regulating bone marrow microenvironment in inhibiting bone metastases (Muz et al., 2021). Additionally, PTH-related peptide is highly related to bone metastasis and leads to chronic pain in patients (Shepherd et al., 2018). While it is also worth noticing that metastasized cancer cells produce PTH-related peptide to induce RANKL, thus accelerating bone resorption, in turn, bone resorption further stimulates the release of tumor growth factors, resulting in promotion of tumor growth in bone and bone metastasis (Takayanagi, 2020). In a word, it is promising to make use of osteoimmunomodulation and target the alterations of the key molecular events that will contribute to a better understanding of the exact role of osteoimmunology in cancer. Future studies are encouraged to pay attention to the crosstalk among innate immune cells, bone resident populations, and cancer cells, which may accelerate the development of therapeutic approaches.

\section{Nervous System}

The connection between osteoimmunology and the nervous system can be reflected in neurogenic heterotopic ossification (NHO), the abnormal bone formation in periarticular muscles, which frequently develops after central nervous system (CNS) injury. Some articles have reported the promising effects of immune regulation in inhibition of heterotopic ossification (Kan et al., 2019; Sorkin et al., 2020); and current studies have established that macrophages, not neutrophils, are 


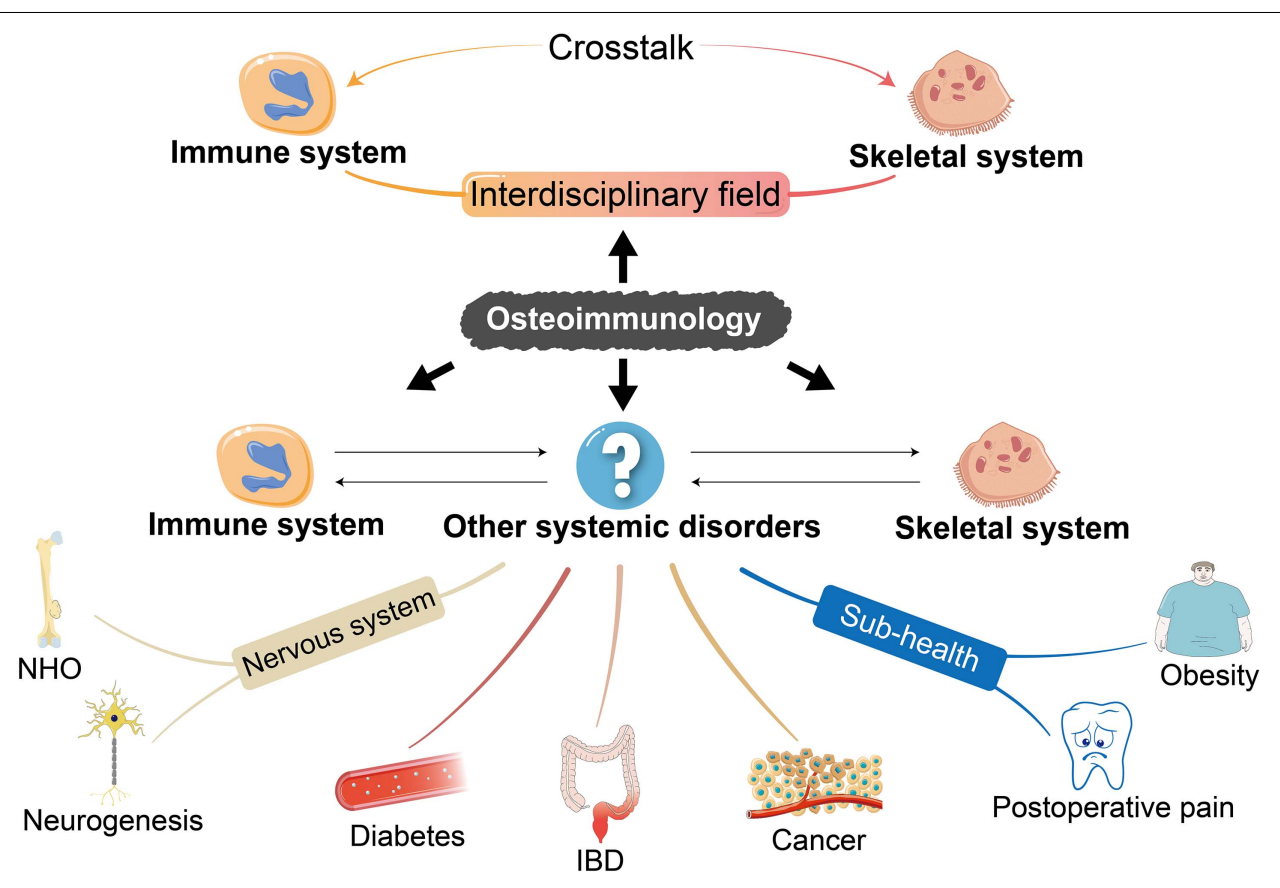

FIGURE 3 | The enrichment of the concept of osteoimmunology. The understanding of some common diseases restricted to immune and skeletal systems from the perspective of osteoimmunology has been enriched in recent years. We propose that the scope of osteoimmunology should involve not only the inner mechanism of primary diseases of the skeletal and immune systems but also other systemic biological processes such as mobilopathy in diabetes, IBD, cancer, NHO, and neurogenesis as well as sub-health status like obesity and postoperative pain after tooth extraction, so as to shed light on the untapped inner mechanism and develop potential therapeutic approaches. IBD, inflammatory bowel disease; $\mathrm{NHO}$, neurogenic heterotopic ossification.

indispensable for NHO development (Genêt et al., 2015; Tseng et al., 2020). While the investigation of the relationship between osteoimmunology and neurogenic regulation has not been thoroughly understood, it seems that few attention is paid to neurogenic bone abnormalities, which is worth further investigation and clarification in the future.

What is more, neurogenesis in bone tissue is also a question of great clinical significance, especially in the oral implantology field. Peri-implant neurogenesis and the reestablishment of neural network is critical to the long-term application of implants for the lack of sensory functions of natural periodontal ligament between implant and bone tissue, avoiding various postoperative complications brought by excessive occlusal force. However, previous studies mainly focused on improving periimplant osteogenesis and osseointegration between natural bone and implant, and researches on osseoperception are rare (A et al., 2018). Most importantly, suitable key targets in this progress still remain unclear. Lysophosphatidic acid (LPA), a physiologic extracellular lipid, mediate Hippo-YAP signaling to play promising regulatory roles in osteoimmunology around implants via LPA receptors (LPARs) (Zhou A. et al., 2020). As for LPAR1, a recent study showed that LPA activated macrophages via LPAR1 and affected immune response in microenvironment (Fransson et al., 2021); LPAR1 was also discovered to mediate the regulation of osteoblast function through downstream YAP signaling (Alioli et al., 2020). Therefore, we suppose that the LPA/LPAR1-YAP axis may have a prospective impact on osteoimmune-mediated osseointegration, but its specific regulatory mechanism needs further clarification. Interestingly, the latest article revealed that LPA/LPAR1 pathway initiated cilia disassembly and promoted neurogenesis by activating the transcriptional coactivators YAP/transcriptional coactivator with a PDZ-binding motif (TAZ) signaling ( $\mathrm{Hu}$ et al., 2021), which suggests the hypothesis that the role of the LPA/LPAR1-YAP pathway in neurogenesis could be generalized to dental implantation field by establishing osseoperception in bone-implant interface in order to compensate for the missing sensory functions of periodontal ligament. Therefore, osseoperception and osteoimmunology might share the same promising signaling target and synergistically promote bone healing and favorable osseointegration, which may be achieved by interdisciplinary work such as producing a pro-neurogenesis surface, which is also friendly to osteoimmunology by surface modification of implants.

\section{Sub-Health Status}

With the development of social economy and the improvement of medical technology, people pay more and more attention to the sub-health status and comfort diagnostic and therapeutic procedures, which raises new requirements on healthcare. For instance, obesity, a common sub-health status, has been proved to undermine both the immune and skeletal systems, and some scientists have started to investigate the inner mechanism and erase potential limitation from the point of view of osteoimmunology (Chan et al., 2012). We propose that it is of great significance to try to 
discover effective approaches against sub-health status, especially in association with osteoimmunomodulation.

Moreover, in order to reduce patients' postoperative pain after tooth extraction, Wang C. W. et al. (2020) and Wang L. et al. (2020) proposed that applying endogenous proresolving mediator Maresin 1 in the extraction socket of mice could accelerate the soft tissue wound closure, promote bone fill of the socket, and preserve the alveolar bone with higher expression of CD206, the surface marker of M2 macrophage. Furthermore, researchers used an innovative method to evaluate the pain intensity of rats and proved that Maresin 1 could reduce postoperative pain (Wang C. W. et al., 2020), suggesting the study value and clinical implications to ease pain and reduce discomfort of patients from the perspective of osteoimmunology.

\section{CONCLUSION}

In short, the concept of osteoimmunology can be further enriched to extend to other systemic diseases beyond the interdisciplinary field of the skeletal and immune systems. Research on the role of osteoimmunology has become the forefront topic in relevant fields since it is of great significance to discuss the pathologic biological processes of related diseases from the point of view of osteoimmunology. We suggest that researchers further clarify how to make use of the key targets

\section{REFERENCES}

A, L., Xu, W., Zhao, J., Li, C., Qi, M., Li, X., et al. (2018). Surface functionalization of $\mathrm{TiO}_{2}$ nanotubes with minocycline and its in vitro biological effects on Schwann cells. Biomed. Eng. OnLine 17:88. doi: 10.1186/s12938-018-0520-6

Albiero, M., Ciciliot, S., Tedesco, S., Menegazzo, L., D’Anna, M., Scattolini, V., et al. (2019). Diabetes-associated myelopoiesis drives stem cell mobilopathy through an OSM-p66Shc signaling pathway. Diabetes 68, 1303-1314. doi: 10.2337/db190080

Albiero, M., Poncina, N., Ciciliot, S., Cappellari, R., Menegazzo, L., Ferraro, F., et al. (2015). Bone marrow macrophages contribute to diabetic stem cell mobilopathy by producing oncostatin M. Diabetes 64, 2957-2968. doi: 10.2337/db141473

Albrektsson, T., Jemt, T., Mölne, J., Tengvall, P., and Wennerberg, A. (2019). On inflammation-immunological balance theory-A critical apprehension of disease concepts around implants: mucositis and marginal bone loss may represent normal conditions and not necessarily a state of disease. Clin. Implant Dent. Relat. Res. 21, 183-189. doi: 10.1111/cid.12711

Alioli, C. A., Demesmay, L., Laurencin-Dalacieux, S., Beton, N., Farlay, D., Follet, H., et al. (2020). Expression of the type 1 lysophosphatidic acid receptor in osteoblastic cell lineage controls both bone mineralization and osteocyte specification. Biochim. Biophys. Acta BBA - Mol. Cell Biol. Lipids 1865:158715. doi: 10.1016/j.bbalip.2020.158715

Arron, J. R., and Choi, Y. (2000). Bone versus immune system. Nature 408, 535-536. doi: 10.1038/35046196

Awang, R. A., Lappin, D. F., MacPherson, A., Riggio, M., Robertson, D., Hodge, P., et al. (2014). Clinical associations between IL-17 family cytokines and periodontitis and potential differential roles for IL-17A and IL-17E in periodontal immunity. Inflamm. Res. 63, 1001-1012. doi: 10.1007/s00011-0140776-7

Bertolini, D. R., Nedwin, G. E., Bringman, T. S., Smith, D. D., and Mundy, G. R. (1986). Stimulation of bone resorption and inhibition of bone formation in vitro by human tumour necrosis factors. Nature 319, 516-518. doi: 10.1038/ $319516 \mathrm{a} 0$ in the aforementioned progresses in future studies, so as to shed light on the untapped mechanism and to develop potential therapeutic strategies for correlated diseases.

\section{AUTHOR CONTRIBUTIONS}

AZ designed the outline and drafted and critically revised the manuscript. BW designed the figures. HY, YT, JL, YJ, and $\mathrm{XY}$ contributed to drafting the manuscript. LX contributed to designing and critically revising the manuscript. All the authors contributed to the article and approved the submitted version.

\section{FUNDING}

This work was supported by grants from the National Natural Science Foundation of China (No. 81701007), Sichuan Science and Technology Program (No. 2021YJ0422), the Fundamental Research Funds for the Central Universities (No. 2018SCUH0006), Research Funding from West China School/Hospital of Stomatology Sichuan University (No. RCDWJS2020-6), and Basic and Applied Basic Research Projects of West China Hospital of Stomatology of Sichuan University (No. RD-02-201902).

Bottini, A., Wu, D. J., Ai, R., Le Roux, M., Bartok, B., Bombardieri, M., et al. (2019). PTPN14 phosphatase and YAP promote TGF $\beta$ signalling in rheumatoid synoviocytes. Ann. Rheum. Dis. 78, 600-609. doi: 10.1136/annrheumdis-2018213799

Bouchet, M., Lainé, A., Boyault, C., Proponnet-Guerault, M., Meugnier, E., Bouazza, L., et al. (2020). ERR $\alpha$ expression in bone metastases leads to an exacerbated antitumor immune response. Cancer Res. 80, 2914-2926. doi: 10. 1158/0008-5472.CAN-19-3584

Brown, B. N., Haschak, M. J., Lopresti, S. T., and Stahl, E. C. (2017). Effects of agerelated shifts in cellular function and local microenvironment upon the innate immune response to implants. Semin. Immunol. 29, 24-32. doi: 10.1016/j.smim. 2017.05.001

Chae, H. J., Chae, S. W., Chin, H. Y., Bang, B. G., Cho, S. B., Han, K. S., et al. (2001). The p38 mitogen-activated protein kinase pathway regulates interleukin-6 synthesis in response to tumor necrosis factor in osteoblasts. Bone 28, 45-53. doi: 10.1016/S8756-3282(00)00413-0

Chan, M. E., Adler, B. J., Green, D. E., and Rubin, C. T. (2012). Bone structure and $\mathrm{B}$-cell populations, crippled by obesity, are partially rescued by brief daily exposure to low-magnitude mechanical signals. FASEB J. 26, 4855-4863. doi: 10.1096/fj.12-209841

Chávez-Galán, L., Olleros, M. L., Vesin, D., and Garcia, I. (2015). Much more than M1 and M2 macrophages, there are also $\mathrm{CD} 169^{+}$and $\mathrm{TCR}^{+}$macrophages. Front. Immunol. 6:263. doi: 10.3389/fimmu.2015. 00263

Chen, X., Chen, L., Tan, J., Shi, D., Ke, T., and Lei, L. (2016). Th17 and Th1 lymphocytes are correlated with chronic periodontitis. Immunol. Invest. 45, 243-254. doi: 10.3109/08820139.2016.1138967

Ciucci, T., Ibáñez, L., Boucoiran, A., Birgy-Barelli, E., Pène, J., Abou-Ezzi, G., et al. (2015). Bone marrow Th17 TNF $\alpha$ cells induce osteoclast differentiation, and link bone destruction to IBD. Gut 64, 1072-1081. doi: 10.1136/gutjnl-2014306947

Coli, P., and Jemt, T. (2021). Are marginal bone level changes around dental implants due to infection? Clin. Implant Dent. Relat. Res. 23, 170-177. doi: $10.1111 /$ cid. 12971 
Croucher, P. I. (2001). Osteoprotegerin inhibits the development of osteolytic bone disease in multiple myeloma. Blood 98, 3534-3540. doi: 10.1182/blood.V98.13. 3534

Culemann, S., Grüneboom, A., Nicolás-Ávila, J. A., Weidner, D., Lämmle, K. F., Rothe, T., et al. (2019). Locally renewing resident synovial macrophages provide a protective barrier for the joint. Nature 572, 670-675. doi: 10.1038/s41586-0191471-1

Danks, L., Komatsu, N., Guerrini, M. M., Sawa, S., Armaka, M., Kollias, G., et al. (2016). RANKL expressed on synovial fibroblasts is primarily responsible for bone erosions during joint inflammation. Ann. Rheum. Dis. 75, 1187-1195. doi: 10.1136/annrheumdis-2014-207137

Delacher, M., Simon, M., Sanderink, L., Hotz-Wagenblatt, A., Wuttke, M., Schambeck, K., et al. (2021). Single-cell chromatin accessibility landscape identifies tissue repair program in human regulatory $\mathrm{T}$ cells. Immunity 54, 702.e17-720.e17. doi: 10.1016/j.immuni.2021.03.007

DiPersio, J. F. (2011). Diabetic stem-cell “mobilopathy.”. N. Engl. J. Med. 365, 2536-2538. doi: 10.1056/NEJMcibr1112347

Dohle, E., Bischoff, I., Böse, T., Marsano, A., Banfi, A., Unger, R., et al. (2014). Macrophage-mediated angiogenic activation of outgrowth endothelial cells in co-culture with primary osteoblasts. Eur. Cell. Mater. 27, 149-165. doi: 10. 22203/eCM.v027a12

Dou, C., Ding, N., Zhao, C., Hou, T., Kang, F., Cao, Z., et al. (2018). Estrogen deficiency-mediated M2 macrophage osteoclastogenesis contributes to M1/M2 ratio alteration in ovariectomized osteoporotic mice. J. Bone Miner. Res. 33, 899-908. doi: 10.1002/jbmr.3364

Dutzan, N., Kajikawa, T., Abusleme, L., Greenwell-Wild, T., Zuazo, C. E., Ikeuchi, T., et al. (2018). A dysbiotic microbiome triggers $\mathrm{T}_{\mathrm{H}} 17$ cells to mediate oral mucosal immunopathology in mice and humans. Sci. Transl. Med. 10:eaat0797. doi: 10.1126/scitranslmed.aat0797

Fadini, G. P., Albiero, M., Seeger, F., Poncina, N., Menegazzo, L., Angelini, A., et al. (2013). Stem cell compartmentalization in diabetes and high cardiovascular risk reveals the role of DPP-4 in diabetic stem cell mobilopathy. Basic Res. Cardiol. 108:313. doi: 10.1007/s00395-012-0313-1

Ferraro, F., Lymperi, S., Mendez-Ferrer, S., Saez, B., Spencer, J. A., Yeap, B. Y., et al. (2011). Diabetes impairs hematopoietic stem cell mobilization by altering niche function. Sci. Transl. Med. 3:104ra101. doi: 10.1126/scitranslmed.3002191

Fransson, J., Gómez-Conde, A. I., Romero-Imbroda, J., Fernández, O., Leyva, L., de Fonseca, F. R., et al. (2021). Activation of macrophages by lysophosphatidic acid through the lysophosphatidic acid receptor 1 as a novel mechanism in multiple sclerosis pathogenesis. Mol. Neurobiol. 58, 470-482. doi: 10.1007/s12035-02002130-x

Gallois, A., Lachuer, J., Yvert, G., Wierinckx, A., Brunet, F., Rabourdin-Combe, C., et al. (2010). Genome-wide expression analyses establish dendritic cells as a new osteoclast precursor able to generate bone-resorbing cells more efficiently than monocytes. J. Bone Miner. Res. 25, 661-672. doi: 10.1359/jbmr.09 0829

Gao, A., Liao, Q., Xie, L., Wang, G., Zhang, W., Wu, Y., et al. (2020). Tuning the surface immunomodulatory functions of polyetheretherketone for enhanced osseointegration. Biomaterials 230:119642. doi: 10.1016/j.biomaterials.2019. 119642

Gao, B., Deng, R., Chai, Y., Chen, H., Hu, B., Wang, X., et al. (2019). Macrophagelineage $\mathrm{TRAP}^{+}$cells recruit periosteum-derived cells for periosteal osteogenesis and regeneration. J. Clin. Invest. 129, 2578-2594. doi: 10.1172/JCI98857

Gawel, D. R., Serra-Musach, J., Lilja, S., Aagesen, J., Arenas, A., Asking, B., et al. (2019). A validated single-cell-based strategy to identify diagnostic and therapeutic targets in complex diseases. Genome Med. 11:47. doi: 10.1186/ s13073-019-0657-3

Genêt, F., Kulina, I., Vaquette, C., Torossian, F., Millard, S., Pettit, A. R., et al. (2015). Neurological heterotopic ossification following spinal cord injury is triggered by macrophage-mediated inflammation in muscle. J. Pathol. 236, 229-240. doi: 10.1002/path.4519

Geng, J., Yu, S., Zhao, H., Sun, X., Li, X., Wang, P., et al. (2017). The transcriptional coactivator TAZ regulates reciprocal differentiation of TH17 cells and Treg cells. Nat. Immunol. 18, 800-812. doi: 10.1038/ni.3748

Goerdt, S., and Orfanos, C. E. (1999). Other functions, other genes: alternative activation of antigen-presenting cells. Immunity 10, 137-142. doi: 10.1016/ S1074-7613(00)80014-X
Goes, P., Dutra, C., Lösser, L., Hofbauer, L. C., Rauner, M., and Thiele, S. (2019). Loss of Dkk-1 in osteocytes mitigates alveolar bone loss in mice with periodontitis. Front. Immunol. 10:2924. doi: 10.3389/fimmu.2019.02924

Gomez Perdiguero, E., Klapproth, K., Schulz, C., Busch, K., Azzoni, E., Crozet, L., et al. (2015). Tissue-resident macrophages originate from yolk-sac-derived erythro-myeloid progenitors. Nature 518, 547-551. doi: 10.1038/nature13989

Gowen, M., Meikle, M. C., and Reynolds, J. J. (1983). Stimulation of bone resorption in vitro by a non-prostanoid factor released by human monocytes in culture. Biochim. Biophys. Acta BBA - Mol. Cell Res. 762, 471-474. doi: 10.1016/0167-4889(83)90014-9

Green, A. C., Rudolph-Stringer, V., Straszkowski, L., Tjin, G., Crimeen-Irwin, B., Walia, M., et al. (2018). Retinoic acid receptor $\gamma$ activity in mesenchymal stem cells regulates endochondral bone, angiogenesis, and B lymphopoiesis. J. Bone Miner. Res. 33, 2202-2213. doi: 10.1002/jbmr.3558

Han, G., Geng, S., Li, Y., Chen, G., Wang, R., Li, X., et al. (2011). $\gamma \delta T$-cell function in sepsis is modulated by C5a receptor signalling: expression of CD88 on mouse $\gamma \delta$ T cells. Immunology 133, 340-349. doi: 10.1111/j.1365-2567.2011.03445.x

Hasegawa, T., Kikuta, J., Sudo, T., Matsuura, Y., Matsui, T., Simmons, S., et al. (2019). Identification of a novel arthritis-associated osteoclast precursor macrophage regulated by FoxM1. Nat. Immunol. 20, 1631-1643. doi: 10.1038/ s41590-019-0526-7

Hirota, K., Hashimoto, M., Ito, Y., Matsuura, M., Ito, H., Tanaka, M., et al. (2018). Autoimmune Th17 cells induced synovial stromal and innate lymphoid cell secretion of the cytokine GM-CSF to initiate and augment autoimmune arthritis. Immunity 48, 1220.e5-1232.e5. doi: 10.1016/j.immuni.2018.04.009

Hsu, Y.-H., Chen, W.-Y., Chan, C.-H., Wu, C.-H., Sun, Z.-J., and Chang, M.S. (2011). Anti-IL-20 monoclonal antibody inhibits the differentiation of osteoclasts and protects against osteoporotic bone loss. J. Exp. Med. 208, 1849-1861. doi: 10.1084/jem.20102234

Hu, H., Song, Z., Song, G., Li, S., Tu, H., Wu, M., et al. (2021). LPA signaling acts as a cell-extrinsic mechanism to initiate cilia disassembly and promote neurogenesis. Nat. Commun. 12:662. doi: 10.1038/s41467-021-20986-y

Ichikawa, Y., Watahiki, J., Nampo, T., Nose, K., Yamamoto, G., Irie, T., et al. (2015). Differences in the developmental origins of the periosteum may influence bone healing. J. Periodontal Res. 50, 468-478. doi: 10.1111/jre.12229

Irelli, A., Sirufo, M. M., Scipioni, T., De Pietro, F., Pancotti, A., Ginaldi, L., et al. (2019). mTOR links tumor immunity and bone metabolism: what are the clinical implications? Int. J. Mol. Sci. 20:5841. doi: 10.3390/ijms20235841

Jabbari, N., Eftekhari, Z., Roodbari, N. H., and Parivar, K. (2020). Evaluation of Encapsulated Eugenol by Chitosan Nanoparticles on the aggressive model of rheumatoid arthritis. Int. Immunopharmacol. 85:106554. doi: 10.1016/j.intimp. 2020.106554

Jiang, Z., Von den Hoff, J. W., Torensma, R., Meng, L., and Bian, Z. (2014). Wnt16 is involved in intramembranous ossification and suppresses osteoblast differentiation through the Wnt/ $\beta$-catenin pathway. J. Cell. Physiol. 229, 384392. doi: 10.1002/jcp. 24460

Jin, S., Chen, H., Li, Y., Zhong, H., Sun, W., Wang, J., et al. (2018). Maresin 1 improves the Treg/Th17 imbalance in rheumatoid arthritis through miR-21. Ann. Rheum. Dis. 77, 1644-1652. doi: 10.1136/annrheumdis-2018-213511

Kan, C., Yang, J., Na, D., Xu, Y., Yang, B., Zhao, H., et al. (2019). Inhibition of immune checkpoints prevents injury-induced heterotopic ossification. Bone Res. 7:33. doi: 10.1038/s41413-019-0074-7

Kartsogiannis, V., Zhou, H., Horwood, N. J., Thomas, R. J., Hards, D. K., Quinn, J. M. W., et al. (1999). Localization of RANKL (receptor activator of NFKB ligand) mRNA and protein in skeletal and extraskeletal tissues. Bone 25, 525-534.

Kaul, N.-C., Mohapatra, S. R., Adam, I., Tucher, C., Tretter, T., Opitz, C. A., et al. (2020). Hypoxia decreases the $T$ helper cell-suppressive capacity of synovial fibroblasts by downregulating IDO1-mediated tryptophan metabolism. Rheumatology 59, 1148-1158. doi: 10.1093/rheumatology/kez587

Khojah, H. M., Ahmed, S., Abdel-Rahman, M. S., and Hamza, A.-B. (2016). Reactive oxygen and nitrogen species in patients with rheumatoid arthritis as potential biomarkers for disease activity and the role of antioxidants. Free Radic. Biol. Med. 97, 285-291. doi: 10.1016/j.freeradbiomed.2016.06.020

Klopfleisch, R. (2016). Macrophage reaction against biomaterials in the mouse model - Phenotypes, functions and markers. Acta Biomater. 43, 3-13. doi: 10.1016/j.actbio.2016.07.003 
Kollet, O., Dar, A., Shivtiel, S., Kalinkovich, A., Lapid, K., Sztainberg, Y., et al. (2006). Osteoclasts degrade endosteal components and promote mobilization of hematopoietic progenitor cells. Nat. Med. 12, 657-664. doi: 10.1038/nm1417

Komatsu, N., Okamoto, K., Sawa, S., Nakashima, T., Oh-hora, M., Kodama, T., et al. (2014). Pathogenic conversion of Foxp $3^{+} \mathrm{T}$ cells into $\mathrm{T}_{\mathrm{H}} 17$ cells in autoimmune arthritis. Nat. Med. 20, 62-68. doi: 10.1038/nm.3432

Kong, Y.-Y., Yoshida, H., Sarosi, I., Tan, H.-L., Timms, E., Capparelli, C., et al. (1999). OPGL is a key regulator of osteoclastogenesis, lymphocyte development and lymph-node organogenesis. Nature 397, 315-323. doi: 10.1038/16852

Könnecke, I., Serra, A., El Khassawna, T., Schlundt, C., Schell, H., Hauser, A., et al. (2014). T and B cells participate in bone repair by infiltrating the fracture callus in a two-wave fashion. Bone 64, 155-165. doi: 10.1016/j.bone.2014.03.052

Kotake, S., Udagawa, N., Takahashi, N., Matsuzaki, K., Itoh, K., Ishiyama, S., et al. (1999). IL-17 in synovial fluids from patients with rheumatoid arthritis is a potent stimulator of osteoclastogenesis. J. Clin. Invest. 103, 1345-1352. doi: 10.1172/JCI5703

Kuboniwa, M., Houser, J. R., Hendrickson, E. L., Wang, Q., Alghamdi, S. A., Sakanaka, A., et al. (2017). Metabolic crosstalk regulates Porphyromonas gingivalis colonization and virulence during oral polymicrobial infection. Nat. Microbiol. 2, 1493-1499. doi: 10.1038/s41564-017-0021-6

Li, H., Sun, T., Liu, C., Cao, Y., and Liu, X. (2020). Photobiomodulation (450 $\mathrm{nm}$ ) alters the infection of periodontitis bacteria via the ROS/MAPK/mTOR signaling pathway. Free Radic. Biol. Med. 152, 838-853. doi: 10.1016/j. freeradbiomed.2020.01.184

Li, J., Yao, M., Zhu, X., Li, Q., He, J., Chen, L., et al. (2019). YAP-induced endothelial-mesenchymal transition in oral submucous fibrosis. J. Dent. Res. 98, 920-929. doi: 10.1177/0022034519851804

Liotta, F., Angeli, R., Cosmi, L., Filì, L., Manuelli, C., Frosali, F., et al. (2008). Toll-like receptors 3 and 4 are expressed by human bone marrow-derived mesenchymal stem cells and can inhibit their T-cell modulatory activity by impairing Notch signaling. Stem Cells 26, 279-289. doi: 10.1634/stemcells.20070454

Liu, B., Zheng, Y., Yin, F., Yu, J., Silverman, N., and Pan, D. (2016). Toll receptormediated Hippo signaling controls innate immunity in drosophila. Cell 164, 406-419. doi: 10.1016/j.cell.2015.12.029

Lories, R. J. U., Derese, I., Ceuppens, J. L., and Luyten, F. P. (2003). Bone morphogenetic proteins 2 and 6, expressed in arthritic synovium, are regulated by proinflammatory cytokines and differentially modulate fibroblast-like synoviocyte apoptosis: BMPs in Chronic Arthritis. Arthritis Rheum. 48, 28072818. doi: 10.1002/art.11389

Löwik, C. W. G. M., van der Pluijm, G., Bloys, H., Hoekman, K., Bijvoet, O. L. M., Aarden, L. A., et al. (1989). Parathyroid hormone (PTH) and PTH-like protein (PLP) stimulate interleukin-6 production by osteogenic cells: a possible role of interleukin-6 in osteoclastogenesis. Biochem. Biophys. Res. Commun. 162, 1546-1552. doi: 10.1016/0006-291X(89)90851-6

Lu, W., Dordai, D., Huso, D., and Desiderio, S. (2018). Smoothened signaling in the mouse osteoblastoid lineage is required for efficient B lymphopoiesis. Blood 131, 323-327. doi: 10.1182/blood-2017-06-793539

Mansour, A., Abou-Ezzi, G., Sitnicka, E., Jacobsen, S. E., Wakkach, A., and BlinWakkach, C. (2012). Osteoclasts promote the formation of hematopoietic stem cell niches in the bone marrow. J. Exp. Med. 209, 537-549. doi: 10.1084/jem. 20110994

Mansour, A., Anginot, A., Mancini, S. J. C., Schiff, C., Carle, G. F., Wakkach, A., et al. (2011). Osteoclast activity modulates B-cell development in the bone marrow. Cell Res. 21, 1102-1115. doi: 10.1038/cr.2011.21

Mantovani, A., Sica, A., Sozzani, S., Allavena, P., Vecchi, A., and Locati, M. (2004). The chemokine system in diverse forms of macrophage activation and polarization. Trends Immunol. 25, 677-686. doi: 10.1016/j.it.2004.09.015

Mantovani, A., Sozzani, S., Locati, M., Allavena, P., and Sica, A. (2002). Macrophage polarization: tumor-associated macrophages as a paradigm for polarized M2 mononuclear phagocytes. Trends Immunol. 23, 549-555. doi: 10.1016/S1471-4906(02)02302-5

Martin, S. K., Fitter, S., El Khawanky, N., Grose, R. H., Walkley, C. R., Purton, L. E., et al. (2018). mTORC1 plays an important role in osteoblastic regulation of B-lymphopoiesis. Sci. Rep. 8:14501. doi: 10.1038/s41598-018-32858-5

Méndez-Ferrer, S., Michurina, T. V., Ferraro, F., Mazloom, A. R., MacArthur, B. D., Lira, S. A., et al. (2010). Mesenchymal and haematopoietic stem cells form a unique bone marrow niche. Nature 466, 829-834. doi: 10.1038/nature09262
Metzger, C. E., Narayanan, A., Zawieja, D. C., and Bloomfield, S. A. (2017). Inflammatory bowel disease in a rodent model alters osteocyte protein levels controlling bone turnover. J. Bone Miner. Res. 32, 802-813. doi: 10.1002/jbmr. 3027

Miller, R. E., Jones, J. C., Tometsko, M., Blake, M. L., and Dougall, W. C. (2014). RANKL inhibition blocks osteolytic lesions and teduces skeletal tumor burden in models of non-small-cell lung cancer bone metastases. J. Thorac. Oncol. 9, 345-354. doi: 10.1097/JTO.0000000000000070

Miyamoto, K., Yoshida, S., Kawasumi, M., Hashimoto, K., Kimura, T., Sato, Y., et al. (2011). Osteoclasts are dispensable for hematopoietic stem cell maintenance and mobilization. J. Exp. Med. 208, 2175-2181. doi: 10.1084/jem. 20101890

Mizoguchi, F., Slowikowski, K., Wei, K., Marshall, J. L., Rao, D. A., Chang, S. K., et al. (2018). Functionally distinct disease-associated fibroblast subsets in rheumatoid arthritis. Nat. Commun. 9:789. doi: 10.1038/s41467-018-02892-y

Monasterio, G., Fernández, B., Castillo, F., Rojas, C., Cafferata, E. A., Rojas, L., et al. (2019). Capsular-defective Porphyromonas gingivalis mutant strains induce less alveolar bone resorption than W50 wild-type strain due to a decreased Th1/Th17 immune response and less osteoclast activity. J. Periodontol. 90, 522-534. doi: 10.1002/JPER.18-0079

Mosser, D. M., and Edwards, J. P. (2008). Exploring the full spectrum of macrophage activation. Nat. Rev. Immunol. 8, 958-969. doi: 10.1038/nri2448

Moutsopoulos, N. M., Kling, H. M., Angelov, N., Jin, W., Palmer, R. J., Nares, S., et al. (2012). Porphyromonas gingivalis promotes Th17 inducing pathways in chronic periodontitis. J. Autoimmun. 39, 294-303. doi: 10.1016/j.jaut.2012.03. 003

Murray, P. J., Allen, J. E., Biswas, S. K., Fisher, E. A., Gilroy, D. W., Goerdt, S., et al. (2014). Macrophage activation and polarization: nomenclature and experimental guidelines. Immunity 41, 14-20. doi: 10.1016/j.immuni.2014.06. 008

Muz, B., Abdelghafer, A., Markovic, M., Yavner, J., Melam, A., Salama, N. N., et al. (2021). Targeting E-selectin to tackle cancer using uproleselan. Cancers 13:335. doi: 10.3390/cancers 13020335

Narayanan, S. A., Metzger, C. E., Bloomfield, S. A., and Zawieja, D. C. (2018). Inflammation-induced lymphatic architecture and bone turnover changes are ameliorated by irisin treatment in chronic inflammatory bowel disease. FASEB J. 32, 4848-4861. doi: 10.1096/fj.201800178R

Nie, H., Zheng, Y., Li, R., Guo, T. B., He, D., Fang, L., et al. (2013). Phosphorylation of FOXP3 controls regulatory T cell function and is inhibited by TNF- $\alpha$ in rheumatoid arthritis. Nat. Med. 19, 322-328. doi: 10.1038/nm.3085

Okamoto, K., Nakashima, T., Shinohara, M., Negishi-Koga, T., Komatsu, N., Terashima, A., et al. (2017). Osteoimmunology: the conceptual framework unifying the immune and skeletal systems. Physiol. Rev. 97, 1295-1349. doi: 10.1152/physrev.00036.2016

Ono, T., Okamoto, K., Nakashima, T., Nitta, T., Hori, S., Iwakura, Y., et al. (2016). IL-17-producing $\gamma \delta \mathrm{T}$ cells enhance bone regeneration. Nat. Commun. 7:10928. doi: $10.1038 /$ ncomms 10928

Owen, K. L., Gearing, L. J., Zanker, D. J., Brockwell, N. K., Khoo, W. H., Roden, D. L., et al. (2020). Prostate cancer cell-intrinsic interferon signaling regulates dormancy and metastatic outgrowth in bone. EMBO Rep. 21:e50162. doi: 10. 15252/embr.202050162

Owen, K. L., and Parker, B. S. (2019). Beyond the vicious cycle: the role of innate osteoimmunity, automimicry and tumor-inherent changes in dictating bone metastasis. Mol. Immunol. 110, 57-68. doi: 10.1016/j.molimm.2017.11.023

Panaroni, C., Fulzele, K., Saini, V., Chubb, R., Pajevic, P. D., and Wu, J. Y. (2015). $\mathrm{PTH}$ signaling in osteoprogenitors is essential for B-lymphocyte differentiation and mobilization. J. Bone Miner. Res. 30, 2273-2286. doi: 10.1002/jbmr.2581

Panaroni, C., and Wu, J. Y. (2013). Interactions between B lymphocytes and the osteoblast lineage in bone marrow. Calcif. Tissue Int. 93, 261-268. doi: 10.1007/ s00223-013-9753-3

Rajendran, M., Looney, S., Singh, N., Elashiry, M., Meghil, M. M., El-Awady, A. R., et al. (2019). Systemic antibiotic therapy reduces circulating inflammatory dendritic cells and Treg-Th17 plasticity in periodontitis. J. Immunol. 202, 2690-2699. doi: 10.4049/jimmunol.1900046

Rivollier, A., Mazzorana, M., Tebib, J., Piperno, M., Aitsiselmi, T., RabourdinCombe, C., et al. (2004). Immature dendritic cell transdifferentiation into osteoclasts: a novel pathway sustained by the rheumatoid arthritis microenvironment. Blood 104, 4029-4037. doi: 10.1182/blood-2004-01-0041 
Roser-Page, S., Vikulina, T., Weiss, D., Habib, M. M., Beck, G. R., Pacifici, R., et al. (2018). CTLA-4Ig (abatacept) balances bone anabolic effects of T cells and Wnt$10 \mathrm{~b}$ with antianabolic effects of osteoblastic sclerostin. Ann. N. Y. Acad. Sci. 1415, 21-33. doi: 10.1111/nyas.13643

Samuel, R. O., Ervolino, E., de Azevedo Queiroz, ÍO., Azuma, M. M., Ferreira, G. T., and Cintra, L. T. A. (2019). Th1/Th2/Th17/Treg balance in apical periodontitis of normoglycemic and diabetic rats. J. Endod. 45, 1009-1015. doi: 10.1016/j. joen.2019.05.003

Santinon, F., Batignes, M., Mebrek, M. L., Biton, J., Clavel, G., Hervé, R., et al. (2020). Involvement of tumor necrosis factor receptor type II in FoxP3 stability and as a marker of Treg cells specifically expanded by anti-tumor necrosis factor treatments in rheumatoid arthritis. Arthritis Rheumatol. 72, 576-587. doi: 10.1002/art.41134

Sato, K., Suematsu, A., Okamoto, K., Yamaguchi, A., Morishita, Y., Kadono, Y., et al. (2006). Th17 functions as an osteoclastogenic helper $\mathrm{T}$ cell subset that links T cell activation and bone destruction. J. Exp. Med. 203, 2673-2682. doi: 10.1084/jem.20061775

Schlundt, C., Reinke, S., Geissler, S., Bucher, C. H., Giannini, C., Märdian, S., et al. (2019). Individual Effector/Regulator $T$ cell ratios impact bone regeneration. Front. Immunol. 10:1954. doi: 10.3389/fimmu.2019.01954

Shang, Z., Qin, D., Li, Q., Zha, X., Pan, L., Peng, D., et al. (2021). Dendrobium huoshanense stem polysaccharide ameliorates rheumatoid arthritis in mice via inhibition of inflammatory signaling pathways. Carbohydr. Polym. 258:117657. doi: 10.1016/j.carbpol.2021.117657

Shepherd, A. J., Mickle, A. D., McIlvried, L. A., Gereau, R. W., and Mohapatra, D. P. (2018). Parathyroid hormone-related peptide activates and modulates TRPV1 channel in human DRG neurons. Eur. J. Pain 22, 1685-1690. doi: 10.1002/ejp. 1251

Shi, C., Zhang, H., Wang, X., Jin, B., Jia, Q., Li, Y., et al. (2020). Cinnamtannin $\mathrm{D} 1$ attenuates autoimmune arthritis by regulating the balance of Th17 and treg cells through inhibition of aryl hydrocarbon receptor expression. Pharmacol. Res. 151:104513. doi: 10.1016/j.phrs.2019.104513

Shioi, A., Teitelbaum, S. L., Ross, F. P., Welgus, H. G., Suzuki, H., Ohara, J., et al. (1991). Interleukin 4 inhibits murine osteoclast formation in vitro. J. Cell. Biochem. 47, 272-277. doi: 10.1002/jcb.240470313

Smith, D. D., Gowen, M., and Mundy, G. R. (1987). Effects of interferon- $\gamma$ and other cytokines on collagen synthesis in fetal rat bone cultures. Endocrinology 120, 2494-2499. doi: 10.1210/endo-120-6-2494

Song, L., Dong, G., Guo, L., and Graves, D. T. (2018). The function of dendritic cells in modulating the host response. Mol. Oral Microbiol. 33, 13-21. doi: 10.1111/omi.12195

Sorkin, M., Huber, A. K., Hwang, C., Carson, W. F., Menon, R., Li, J., et al. (2020). Regulation of heterotopic ossification by monocytes in a mouse model of aberrant wound healing. Nat. Commun. 11:722. doi: 10.1038/s41467-01914172-4

Souto, G. R., Queiroz-Junior, C. M., de Abreu, M. H. N. G., Costa, F. O., and Mesquita, R. A. (2014). Pro-inflammatory, Th1, Th2, Th17 cytokines and dendritic cells: a cross-sectional study in chronic periodontitis. PLoS One 9:e91636. doi: 10.1371/journal.pone.0091636

Suda, T., Takahashi, N., Udagawa, N., Jimi, E., Gillespie, M. T., and Martin, T. J. (1999). Modulation of osteoclast differentiation and function by the new members of the tumor necrosis factor receptor and ligand families. Endocr. Rev. 20, 345-357. doi: 10.1210/edrv.20.3.0367

Sugiyama, T., Kohara, H., Noda, M., and Nagasawa, T. (2006). Maintenance of the hematopoietic stem cell pool by CXCL12-CXCR4 chemokine signaling in bone marrow stromal cell niches. Immunity 25, 977-988. doi: 10.1016/j.immuni. 2006.10.016

Sutton, C. E., Lalor, S. J., Sweeney, C. M., Brereton, C. F., Lavelle, E. C., and Mills, K. H. G. (2009). Interleukin-1 and IL-23 induce innate IL-17 production from $\gamma \delta \mathrm{T}$ cells, amplifying Th17 responses and autoimmunity. Immunity 31, 331-341. doi: 10.1016/j.immuni.2009.08.001

Sylvester, F. A. (2017). "Inflammatory bowel disease: effects on bone and mechanisms," in Understanding the Gut-Bone Signaling Axis Advances in Experimental Medicine and Biology, eds L. R. McCabe and N. Parameswaran (Cham: Springer International Publishing), 133-150.

Takayama, K., Inoue, T., Narita, S., Maita, S., Huang, M., Numakura, K., et al. (2017). Inhibition of the RANK/RANKL signaling with osteoprotegerin prevents castration-induced acceleration of bone metastasis in castrationinsensitive prostate cancer. Cancer Lett. 397, 103-110. doi: 10.1016/j.canlet. 2017.03.034

Takayanagi, H. (2007). Osteoimmunology: shared mechanisms and crosstalk between the immune and bone systems. Nat. Rev. Immunol. 7, 292-304. doi: $10.1038 /$ nri2062

Takayanagi, H. (2020). Osteoimmunology - Bidirectional dialogue and inevitable union of the fields of bone and immunity. Proc. Jpn. Acad. Ser. B 96, 159-169. doi: $10.2183 /$ pjab.96.013

Tätting, L., Sandberg, O., Bernhardsson, M., Ernerudh, J., and Aspenberg, P. (2017). Isolated metaphyseal injury influences unrelated bones: a flow cytometric study of tibia and humerus in mice. Acta Orthop. 88, 223-230. doi: 10.1080/17453674.2016.1274587

Tian, B., Wang, N., Jiang, Q., Tian, L., Hu, L., and Zhang, Z. (2021). The immunogenic reaction and bone defect repair function of $\varepsilon$-poly-L-lysine (EPL)-coated nanoscale PCL/HA scaffold in rabbit calvarial bone defect. J. Mater. Sci. Mater. Med. 32:63. doi: 10.1007/s10856-021-06533-7

Trindade, R., Albrektsson, T., Galli, S., Prgomet, Z., Tengvall, P., and Wennerberg, A. (2018). Osseointegration and foreign body reaction: titanium implants activate the immune system and suppress bone resorption during the first 4 weeks after implantation. Clin. Implant Dent. Relat. Res. 20, 82-91. doi: 10.1111/ cid. 12578

Tseng, H., Kulina, I., Salga, M., Fleming, W., Vaquette, C., Genêt, F., et al. (2020). Neurogenic heterotopic ossifications develop independently of granulocyte colony-stimulating factor and neutrophils. J. Bone Miner. Res. 35, 2242-2251. doi: 10.1002/jbmr.4118

Tsukasaki, M. (2020). RANKL and osteoimmunology in periodontitis. J. Bone Miner. Metab. 39, 82-90. doi: 10.1007/s00774-020-01165-3

Tsukasaki, M., Huynh, N. C.-N., Okamoto, K., Muro, R., Terashima, A., Kurikawa, Y., et al. (2020). Stepwise cell fate decision pathways during osteoclastogenesis at single-cell resolution. Nat. Metab. 2, 1382-1390.

Tsukasaki, M., and Takayanagi, H. (2019). Osteoimmunology: evolving concepts in bone-immune interactions in health and disease. Nat. Rev. Immunol. 19, 626-642. doi: 10.1038/s41577-019-0178-8

van Bodegraven, A. A., and Bravenboer, N. (2020). Perspective on skeletal health in inflammatory bowel disease. Osteoporos. Int. 31, 637-646. doi: 10.1007/s00198019-05234-w

Vanegas-Acosta, J. C., Landinez, P., and Garzón-Alvarado, D. A. (2010). Mathematical model of the coagulation in the bone-dental implant interface. Comput. Biol. Med. 40, 791-801. doi: 10.1016/j.compbiomed.2010.08.002

Vasam, G., Joshi, S., Thatcher, S. E., Bartelmez, S. H., Cassis, L. A., and Jarajapu, Y. P. R. (2017). Reversal of bone marrow mobilopathy and enhanced vascular repair by angiotensin-(1-7) in diabetes. Diabetes 66, 505-518. doi: 10.2337/ db16-1039

Vi, L., Baht, G. S., Soderblom, E. J., Whetstone, H., Wei, Q., Furman, B., et al. (2018). Macrophage cells secrete factors including LRP1 that orchestrate the rejuvenation of bone repair in mice. Nat. Commun. 9:5191. doi: 10.1038/ s41467-018-07666-0

Walsh, M. C., Takegahara, N., Kim, H., and Choi, Y. (2018). Updating osteoimmunology: regulation of bone cells by innate and adaptive immunity. Nat. Rev. Rheumatol. 14, 146-156. doi: 10.1038/nrrheum.2017.213

Wang, B., Lin, J., Zhang, Q., Zhang, X., Yu, H., Gong, P., et al. (2019). aCGRP affects BMSCs' migration and osteogenesis via the Hippo-YAP pathway. Cell Transplant. 28, 1420-1431. doi: 10.1177/0963689719871000

Wang, C. W., Yu, S. H., Fretwurst, T., Larsson, L., Sugai, J. V., Oh, J., et al. (2020). Maresin 1 promotes wound healing and socket bone regeneration for alveolar ridge preservation. J. Dent. Res. 99, 930-937. doi: 10.1177/0022034520917903

Wang, L., Zheng, J., Pathak, J. L., Chen, Y., Liang, D., Yang, L., et al. (2020). SLIT2 overexpression in periodontitis intensifies inflammation and alveolar bone loss, possibly via the activation of MAPK pathway. Front. Cell Dev. Biol. 8:593. doi: $10.3389 /$ fcell.2020.00593

Wang, Y., Xiao, M., Tao, C., Chen, J., Wang, Z., Yang, J., et al. (2018). Inactivation of mTORC1 signaling in osterix-expressing cells impairs B-cell differentiation. J. Bone Miner. Res. 33, 732-742. doi: 10.1002/jbmr.3352

Wei, K., Korsunsky, I., Marshall, J. L., Gao, A., Watts, G. F. M., Major, T., et al. (2020). Notch signalling drives synovial fibroblast identity and arthritis pathology. Nature 582, 259-264. doi: 10.1038/s41586-020-2222-z 
Williams, D. F. (2008). On the mechanisms of biocompatibility. Biomaterials 29, 2941-2953. doi: 10.1016/j.biomaterials.2008.04.023

Wu, J. Y., Purton, L. E., Rodda, S. J., Chen, M., Weinstein, L. S., McMahon, A. P., et al. (2008). Osteoblastic regulation of B lymphopoiesis is mediated by $\mathrm{G}_{s} \alpha-$ dependent signaling pathways. Proc. Natl. Acad. Sci. U.S.A. 105, 16976-16981. doi: 10.1073/pnas.0802898105

Wu, X., Chen, H., Wang, Y., and Gu, Y. (2020). Akt2 affects periodontal inflammation via altering the M1/M2 ratio. J. Dent. Res. 99, 577-587. doi: $10.1177 / 0022034520910127$

Xiang, L., Yu, H., Zhang, X., Wang, B., Yuan, Y., Zhang, Q., et al. (2018). The versatile hippo pathway in oral-maxillofacial development and bone remodeling. Dev. Biol. 440, 53-63. doi: 10.1016/j.ydbio.2018.05.017

Xiao, L., Zhou, Y., Friis, T., Beagley, K., and Xiao, Y. (2019). S1P-S1PR1 signaling: the "sphinx" in osteoimmunology. Front. Immunol. 10:1409. doi: 10.3389/ fimmu.2019.01409

Xiong, J., Onal, M., Jilka, R. L., Weinstein, R. S., Manolagas, S. C., and O’Brien, C. A. (2011). Matrix-embedded cells control osteoclast formation. Nat. Med. 17, 1235-1241. doi: 10.1038/nm.2448

Yahara, Y., Barrientos, T., Tang, Y. J., Puviindran, V., Nadesan, P., Zhang, H., et al. (2020). Erythromyeloid progenitors give rise to a population of osteoclasts that contribute to bone homeostasis and repair. Nat. Cell Biol. 22, 49-59. doi: 10.1038/s41556-019-0437-8

Yamaguchi, T., Movila, A., Kataoka, S., Wisitrasameewong, W., Ruiz Torruella, M., Murakoshi, M., et al. (2016). Proinflammatory M1 macrophages inhibit RANKL-induced osteoclastogenesis. Infect. Immun. 84, 2802-2812. doi: 10. 1128/IAI.00461-16

Yang, D., and Wan, Y. (2019). Molecular determinants for the polarization of macrophage and osteoclast. Semin. Immunopathol. 41, 551-563. doi: 10.1007/ s00281-019-00754-3

Yang, J., Park, O., Kim, J., Kwon, Y., Yun, C., and Han, S. H. (2019). Modulation of macrophage subtypes by IRF5 determines osteoclastogenic potential. J. Cell. Physiol. 234, 23033-23042. doi: 10.1002/jcp.28863

Yasuda, H., Shima, N., Nakagawa, N., Yamaguchi, K., Kinosaki, M., Mochizuki, S.-I., et al. (1998). Osteoclast differentiation factor is a ligand for osteoprotegerin/osteoclastogenesis-inhibitory factor and is identical to TRANCE/RANKL. Proc. Natl. Acad. Sci. U.S.A. 95, 3597-3602. doi: 10.1073/pnas.95.7.3597

Yu, L., Tu, Q., Han, Q., Zhang, L., Sui, L., Zheng, L., et al. (2015). Adiponectin regulates bone marrow mesenchymal stem cell niche through a unique signal transduction pathway: an approach for treating bone disease in diabetes. Stem Cells 33, 240-252. doi: 10.1002/stem.1844

Yu, W., Zhong, L., Yao, L., Wei, Y., Gui, T., Li, Z., et al. (2021). Bone marrow adipogenic lineage precursors promote osteoclastogenesis in bone remodeling and pathologic bone loss. J. Clin. Invest. 131:e140214. doi: 10.1172/JCI140214
Yuan, Y., Jiang, Y., Wang, B., Guo, Y., Gong, P., and Xiang, L. (2020). Deficiency of calcitonin gene-related peptide affects macrophage polarization in osseointegration. Front. Physiol. 11:733. doi: 10.3389/fphys.2020.00733

Zhang, F., Wei, K., Slowikowski, K., Fonseka, C. Y., Rao, D. A., Kelly, S., et al. (2019). Defining inflammatory cell states in rheumatoid arthritis joint synovial tissues by integrating single-cell transcriptomics and mass cytometry. Nat. Immunol. 20, 928-942. doi: 10.1038/s41590-019-0378-1

Zhao, D., Zuo, K., Wang, K., Sun, Z., Lu, Y.-P., Cheng, L., et al. (2021). Interleukin4 assisted calcium-strontium-zinc-phosphate coating induces controllable macrophage polarization and promotes osseointegration on titanium implant. Mater. Sci. Eng. C 118:111512. doi: 10.1016/j.msec.2020.111512

Zheng, J., Yu, H., Zhou, A., Wu, B., Liu, J., Jia, Y., et al. (2020). It takes two to tango: coupling of Hippo pathway and redox signaling in biological process. Cell Cycle 19, 2760-2775. doi: 10.1080/15384101.2020.1824448

Zhou, A., Yu, H., Liu, J., Zheng, J., Jia, Y., Wu, B., et al. (2020). Role of HippoYAP signaling in osseointegration by regulating osteogenesis, angiogenesis, and osteoimmunology. Front. Cell Dev. Biol. 8:780. doi: 10.3389/fcell.2020.00 780

Zhou, W., Shen, Q., Wang, H., Yang, J., Zhang, C., Deng, Z., et al. (2020). Knockdown of YAP/TAZ inhibits the migration and invasion of fibroblast synovial cells in rheumatoid arthritis by regulating autophagy. J. Immunol. Res. 2020, 1-11. doi: 10.1155/2020/9510594

Zhu, Y., Liang, H., Liu, X., Wu, J., Yang, C., Wong, T. M., et al. (2021). Regulation of macrophage polarization through surface topography design to facilitate implant-to-bone osteointegration. Sci. Adv. 7:eabf6654. doi: 10.1126/sciadv. abf6654

Conflict of Interest: The authors declare that the research was conducted in the absence of any commercial or financial relationships that could be construed as a potential conflict of interest.

Publisher's Note: All claims expressed in this article are solely those of the authors and do not necessarily represent those of their affiliated organizations, or those of the publisher, the editors and the reviewers. Any product that may be evaluated in this article, or claim that may be made by its manufacturer, is not guaranteed or endorsed by the publisher.

Copyright $\odot 2021$ Zhou, Wu, Yu, Tang, Liu, Jia, Yang and Xiang. This is an openaccess article distributed under the terms of the Creative Commons Attribution License (CC BY). The use, distribution or reproduction in other forums is permitted, provided the original author(s) and the copyright owner(s) are credited and that the original publication in this journal is cited, in accordance with accepted academic practice. No use, distribution or reproduction is permitted which does not comply with these terms. 